\title{
Long-Run Impacts of Childhood Access to the Safety Net $^{\dagger}$
}

\author{
By Hilary Hoynes, Diane Whitmore Schanzenbach, \\ AND Douglas Almond*
}

\begin{abstract}
We examine the impact of a positive and policy-driven change in economic resources available in utero and during childhood. We focus on the introduction of the Food Stamp Program, which was rolled out across counties between 1961 and 1975. We use the Panel Study of Income Dynamics to assemble unique data linking family background and county of residence in early childhood to adult health and economic outcomes. Our findings indicate access to food stamps in childhood leads to a significant reduction in the incidence of metabolic syndrome and, for women, an increase in economic selfsufficiency. (JEL I12, I38, J24)
\end{abstract}

There is substantial evidence on the strong intergenerational correlations in health and income. As documented by Case, Lubotsky, and Paxson (2002), health and economic disparities unfold early in life. There is less evidence, however, on causal mechanisms behind this gap. The "early origins" literature offers some guidance toward the causal relationships underlying intergenerational correlations. The extent to which policies aimed at improving early life conditions can improve long-term health and economic outcomes is of great interest, and a growing literature in this area seeks to better understand these linkages.

In this paper, we evaluate whether increasing the family's economic resources when a child is in utero and during childhood improves later life health and economic outcomes. In particular, we focus on the introduction of a key element of

\footnotetext{
*Hoynes: University of California, Berkeley, 2607 Hearst Ave., \#7320, Berkeley, CA 94720, and NBER (e-mail: hoynes@ berkeley.edu); Schanzenbach: Northwestern University, 2120 Campus Drive, Evanston, IL 60208, and NBER (e-mail: dws@ northwestern.edu); Almond: Columbia University, 420 West 118th Street, New York, NY 10027 (e-mail: da2152@columbia.edu). We thank Rucker Johnson, Bhash Mazumder, Doug Miller, Jesse Rothstein, Caroline Hoxby, and seminar participants at Northwestern University, Princeton University, UC Davis Center for Poverty Research, UCSB, UC Berkeley, Stanford, University of Stavanger, the Goldman School, University College London, and the University of Michigan for helpful comments. We are grateful to Bob Schoeni and Donna Nordquist for help with the PSID, Karen Norberg for help identifying deaths due to nutritional deficiencies, Martha Bailey and Andrew Goodman-Bacon for sharing data on rollout of Community Health Centers, and Amy Finkelstein and Jean Roth for sharing American Hospital Association Annual Survey data. This work was supported by NSF Career Award SES-0847329 (Almond), USDA FANRP Project 235, "Impact of Food Stamps and WIC on Health and Long Run Economic Outcomes," the University of Michigan PSID Small Grant Program, the UC Davis Center for Poverty Research, and UC Davis Committee on Research New Research Initiative. We appreciate the excellent research assistance of Charles Stoecker, Ankur Patel, Danielle Sandler, and Andrew Foote. This paper was previously circulated under the title of "Long Run Economic and Health Impacts of Participation in the Food Stamp Program." The authors declare that they have no relevant or material financial interests that relate to the research described in this paper. This study is covered by UC Berkeley IRB approval 2013-09-5644. Confidential data from the Panel Study of Income Dynamics was received under contract N017046-07.

${ }^{\dagger}$ Go to http://dx.doi.org/10.1257/aer.20130375 to visit the article page for additional materials and author disclosure statement(s).
} 
the US safety net, the Food Stamp Program (FSP). The FSP was rolled out in a county-by-county basis between 1962 and 1975, providing low-income families with vouchers that could be used at grocery stores to purchase food. Both economic theory and prior empirical evidence (using the same FSP rollout identification strategy adopted in this paper) suggest that these vouchers increase the total resources available to a household, and are treated the same as an equivalent cash income transfer would be (Hoynes and Schanzenbach 2009). Thus, we can utilize the FSP rollout as an identification strategy for increases in economic resource availability early in life. Our analysis builds on previous research finding a positive "firststage" effect of FSP rollout on contemporaneous health, as measured in natality data by birth weight (Almond, Hoynes, and Schanzenbach 2011; Currie and Moretti 2008), though outcomes in adulthood need not operate solely though that channel (Almond, Chay, and Lee 2005; Almond and Currie 2011b). The program rollout design links the paper to a growing literature evaluating the introduction of other Great Society programs. ${ }^{1}$

Our analysis also makes three important contributions to the literature that relates resources in utero and during childhood to economic and health outcomes in adulthood. First, much of the early design-based observational studies looked at extreme, negative events including famines, natural disaster, or disease outbreaks (see Currie 2009 and Almond and Currie 2011a,b for recent reviews). More recently, studies have examined the long-term effects of positive, policy-driven treatments such as early childhood education (Ludwig and Miller 2007; Campbell et al. 2014); Medicaid (Brown, Kowalski, and Lurie 2015; Meyer and Wherry 2012); early twentieth century welfare benefits (Aizer et al. 2016); environmental policies (Isen, Rossin-Slater, and Walker forthcoming); alcohol availability (Nilsson forthcoming); and reduced infectious disease burden (Almond, Currie, and Hermann 2012). ${ }^{2}$ We extend the literature by examining the impact of a central element of the US safety net, and currently our only universal welfare program (Hoynes and Schanzenbach forthcoming). We know little about the Food Stamp Program yet, after Social Security, it touches more families than about any other element of the social safety net. Second, because our policy experiment is essentially a disposable income transfer to low-income households containing young children, the results shed light on the causal impact of increased income during childhood on long-term outcomes. Third, our treatment extends beyond in utero exposure; we can test whether the impacts of exposure to food stamps vary throughout childhood examining when treatment matters. ${ }^{3}$

The Food Stamp Program, recently renamed Supplemental Nutrition Assistance Program (SNAP), is the fundamental safety net in the United States. Importantly,

\footnotetext{
${ }^{1}$ Other rollout studies examine Head Start (Ludwig and Miller 2007); Medicare (Almond, Chay, and Greenstone 2007; Finkelstein and McKnight 2008); Women, Infants, and Children (WIC) (Hoynes, Page, and Stevens 2011); family planning programs (Bailey 2012); Title I (Cascio et al. 2010); and community health centers (Bailey and Goodman-Bacon 2015).

${ }^{2}$ Other studies analyzing the longer-run impacts of positive policy treatments examine compulsory schooling laws (Lleras-Muney 2005; Clark and Royer 2013); introduction of unleaded gasoline (Reyes 2007; Nilsson 2009); and Medicare-induced hospital desegregation (Chay, Guryan, and Mazumder 2009).

${ }^{3}$ There is also an important literature on height and stunting, and the potential for "catch-up growth" (see, e.g., Case and Paxson 2008 and Tanner 1981). Our ability to speak to this literature is limited, however, by the low incidence of stunting, the birth cohorts in our sample, and the fact that, in our analysis, once treatment turns on it does not turn off.
} 
it is the only public assistance program that is available to all income-eligible families (other programs limit eligibility to particular groups such as female-headed households, children, the disabled, or the elderly). It is currently the largest US cash or near cash means-tested transfer program with spending in 2012 of \$74 billion compared to $\$ 29$ billion for Temporary Assistance for Needy Families (TANF) and $\$ 64$ billion for the federal Earned Income Tax Credit (EITC). ${ }^{4}$ In 2013, food stamps lifted five million people out of poverty, behind only Social Security and the EITC in its antipoverty effects (Short 2014). Additionally, food stamps played an important role in protecting families in the Great Recession (Bitler and Hoynes 2015). Interestingly, in contrast to the rest of the US safety net, the FSP is a federal program and exhibits little variation across states (Currie 2003). It also has remained largely intact in the presence of dramatic reforms to other parts of the safety net (Bitler and Hoynes 2010). This lack of variation across states and over time presents significant challenges for evaluating the impacts of the FSP (Currie 2003), and as a result the program is tremendously understudied in the economics literature.

Our main results are for a sample of adults born between 1956 and 1981 who grew up in disadvantaged families (their parent had less than a high school education). We refer to this as the "high-participation sample." We employ a difference-in-differences model where the treatment varies by county of birth and birth cohort, and we include controls for county and year of birth and interview fixed effects, state-linear time trends, and county-year of birth controls. We also stratify on other measures of disadvantage at the individual and county level in a difference-in-differences framework. In addition, we estimate a triple-difference model that extends beyond the low education sample and uses variation across subgroups with varying propensities of being affected by food stamps (Hoynes and Schanzenbach 2009). Our main treatment variable is the share of time between conception and age five that a Food Stamp Program was available in the individual's county of birth. We estimate impacts on weight, height, stunting, general health status, disability, the incidence of many conditions and diseases (e.g., high blood pressure, diabetes, heart disease, etc.), health behaviors (smoking, drinking), as well as education, earnings, income, and program participation. Because of the many outcome variables, we follow Kling, Liebman, and Katz (2007) and Anderson (2008) and estimate summary standardized indices that aggregate information over multiple treatments.

We find that access to the FSP in utero and in early childhood leads to a large and statistically significant reduction in the incidence of "metabolic syndrome" (a cluster of conditions including obesity, high blood pressure, heart disease, and diabetes) as well as an increase in reporting to be in good health. The United States is facing high levels of obesity, described by many as a "public health crisis," and our results show that addressing nutrition in early life through a policy program can have a positive effect on the problem. We also find for women that access to food stamps in early childhood leads to an increase in economic self-sufficiency.

\footnotetext{
${ }^{4}$ Food stamp participation has increased to historic highs during the Great Recession: in 2007, expenditures on food stamps, at $\$ 31$ billion, compared to $\$ 48$ billion for the EITC and $\$ 27$ billion for TANF. Program costs are found in US Department of Health and Human Services (2012), Internal Revenue Service (2012), and US Department of Agriculture (2012).
} 
Our results are robust to adding a rich set of county controls (possible confounders), and event-study models further support the validity of the research design. Further, we find important results concerning the timing of exposure-the beneficial impacts of food stamps are concentrated in exposure during the period ranging from in utero through early childhood, with limited additional impacts after that time frame.

Our results not only make a contribution by establishing a link between increased economic resources in childhood and long-run health and economic outcomes, but we also can speak to the "program evaluation" of the FSP by quantifying aspects of long-term internal and external benefits of the safety net that have not previously been measured. Our work shows that the FSP generates larger private and social benefits when taking into account the "multiplier effect" on later life outcomes.

The remainder of our paper is as follows. In Section I we summarize the economic literature on long-term effects of early life interventions. In Section II we summarize the biological science literature in order to provide guidance for which health outcomes are expected to be impacted by the FSP treatment. In Section III we provide the background on the FSP and in Section IV we describe our data. In Section V we present our empirical model and Section VI our results. We conclude in Section VII.

\section{Background and Prior Research}

That in utero and early childhood events can have important vestigial effects has been documented for a wide range of later life outcomes, including health status, test scores, education attainment, wages, and mortality. Most of the early studies leveraged short, extreme events experienced in utero as identification strategies (see reviews by Currie 2009 and Almond and Currie 2011a,b). Examples include famine (Stein et al. 1975; Susser and Lin 1992; Painter, Roseboom, and Bleker 2005; Chen and Zhou 2007); disease (Almond 2006; Barreca 2010); and radiation (Almond, Edlund, and Palme 2009). A natural question is how generalizable such linkages are, and in particular whether more routine childhood experiences may also shape health and economic outcomes during adulthood. Evidence from famines may be especially difficult to interpret because they typically are less "clean" natural experiments, with diffuse start and end points, endogenous migration, and high levels of sample attrition.

There is less work that combines the strength of design-based identification strategies for causal inference with more commonplace treatments/exposures, particularly those that are driven by policy. The shortage of previous work stems from the challenge of marrying identification strategies for program evaluation to (i) policies that affect children at a young age, and (ii) policies that can be mapped to data on later life outcomes in adulthood. Thus, we are still at the beginning stages of learning what type of shocks, in what setting, and during what point in early life matter for long-term health and economic outcomes.

The understanding of the long-term effects of positive, policy-based treatments is quickly changing in this active literature. In particular, there are a handful of studies that are closest to our own. Ludwig and Miller (2007), using the introduction of Head Start in the poorest US counties, find the program reduced childhood 
mortality rates and increased educational attainment. ${ }^{5}$ Campbell et al. (2014) follow a cohort experimentally assigned to attend the Abecedarian Project, a high-quality preschool program in North Carolina, and find strong improvements in adult health. Meyer and Wherry (2012) find that Medicaid expansions reduce mortality rates among black teens and Brown, Kowalski, and Lurie (2015) find that the Medicaid and State Children's Health Insurance Program expansions in the 1980s and early 1990s increased economic and educational outcomes by age 28. Isen, Rossin-Slater, and Walker (forthcoming) find that reductions in early life exposure to air pollution, identified by the 1970 Clean Air Act, led to improvements in employment and earnings for workers by age 30. Nilsson (forthcoming) finds that a policy-driven increase in alcohol availability during pregnancy leads to reductions in employment, earnings, and education in adulthood. Chetty et al. (2011) and Dynarski, Hyman, and Schanzenbach (2013) find persistent effects of class-size reductions at 5-8 years old on educational attainment and initial labor market outcomes.

Additionally, Reyes (2007) and Nilsson (2009) consider the effect of early childhood lead exposure on later life outcomes, and Glied and Neidell (2010) evaluate the long-term impacts of water fluoridation. Chay, Guryan, and Mazumder (2009) find that improved health for young black children during the late 1960s and early 1970s yielded substantially increased National Assessment of Educational Progress (NAEP) and Armed Forces Qualification Test (AFQT) test scores during the 1980s. Building on Almond, Chay, and Greenstone (2007), they argue that improved access to hospitals following the Civil Rights Act and Medicare-induced desegregation of hospitals drove the reduction in post-neonatal mortality rates for blacks that subsequently yielded higher test scores. Likewise, more specific medical interventions in the early postnatal period have been found to exert long-term effects, including surfactant and related treatments for very low birth weight infants (Bharadwaj, Løken, and Nielson 2013) and breastfeeding-encouragement by hospital nurses following delivery (Fitzsimons and Vera-Hernández 2014). Additionally, Almond, Currie, and Herman (2012) consider improvements in post-neonatal mortality in the 1960s and 1970s United States, which were driven by various factors including access to medical care. Focusing on how these improvements differed by race, they found that improvements in early life disease environment decreased the incidence of diabetes during pregnancy (i.e., when the exposed cohort reached adulthood) for blacks.

A second strand of research, relevant for our study, considers the effect of income on health. Much of this literature is concerned with the short-term effects of income changes experienced in adulthood, and there are few studies that consider the long-term effect of early life income changes. Van den Berg, Lindeboom, and Portrait (2006) compare Dutch mortality rates among those born during economic downturns to those born during expansions. Those born during expansions lived substantially longer, which they argue is not due to changes in cohort composition or other potential confounders. Banerjee et al. (2010) consider the nineteenth century blight of French vineyards that created a region by birth cohort varying shock to production and hence income. They find this led to shorter heights in adulthood but no impact on mortality.

\footnotetext{
${ }^{5}$ Carneiro and Ginja (2014) find that Head Start exposure reduces subsequent obesity among males measured at ages 12 to 13 .
} 


\section{Impacts of Early Nutrition and Expected Effects of the FSP}

Causal mechanisms by which early childhood events affect later life are best understood for nutrition. This section reviews specific mechanisms by which early malnutrition can impair development with long-term consequences. Although the FSP was clearly a program designed to improve nutritional intake among recipients, economic theory suggests that in-kind transfers are treated as cash for recipients who are inframarginal. As a result, the long-term impacts of the FSP may also be mediated through other pathways such as family stress reduction (Evans and Garthwaite 2014) or reduced maternal employment (Hoynes and Schanzenbach 2012) in addition to through nutrition pathways.

Using the same program introduction design adopted in this paper (described below), Hoynes and Schanzenbach (2009) find that the introduction of the FSP increased households' spending on food. But, because most recipients received a food stamp benefit below their normal food expenditures, they also find that the increase in food spending is in line with what one would expect from a cash income transfer. We argue, then, that the program is better understood as an income transfer program than a more narrow nutrition program, and its introduction can be thought of as an increase in economic resources. However, keep in mind that because recipients were by definition poor, a large portion of their FSP benefit was spent on food and thus many of the mechanisms at work can be expected to run through nutrition pathways.

At the time the FSP was introduced, hunger and nutritional deficiencies were not uncommon among Americans. For example, a survey of low-income families in Texas, Louisiana, Kentucky, and West Virginia during the period 1968-1970 found that 15 percent of whites and 37 percent of blacks had low hemoglobin levels as well as relatively high rates of deficiencies in vitamin $\mathrm{C}$, riboflavin, and protein (Eisinger 1998). The 1968 CBS documentary Hunger in America raised national awareness of the problem and possibly influenced the policy debate on the FSP (Berry 1984). Here, by briefly summarizing the linkages between early life nutrition and later life outcomes, we provide predictions about outcomes that may be altered by our FSP treatment.

Some linkages between early life nutrition and later life outcomes are fairly intuitive. For example, severely undernourished children may suffer from anemia and listlessness. This may reduce their ability to invest in learning during childhood and may harm their long-run earnings and other outcomes. Another long understood mechanism is rickets, caused by prolonged vitamin D deficiency, which causes weakening of bones in children and leads to stunting of growth, skeletal deformities, and other long-term poor health outcomes. To be sure, the longer-run health impacts of poor nutrition during early life were in part understood prior to the introduction of the Food Stamp Program. During World War II, for example, high numbers of young men were excluded from active military service because of health conditions thought caused by the poor nutrition they experienced during the Great Depression, and as a result the issue of adequate nutrition became a national security concern. Shortly thereafter, Congress passed the National School Lunch Act citing as its purpose "to protect the health and welfare of the children of the United States" (Galer-Unti 1995). 
Poor early life nutrition may also directly harm long-run outcomes through altering the body's developmental trajectory. There is an emerging scientific consensus that describes critical periods of development during early life that "program" the body's long-term survival outcomes (Barker 1992; Gluckman and Hanson 2004). During development, the fetus (and postnatally the child) may take cues from the current environment to predict the type of environment it is expected to face in the long run and in some cases adapts its formation to better thrive in the expected environment (Gluckman and Hanson 2004). A problem arises, however, when the predicted later environment and the actual later environment are substantially different. For example, if nutrients are scarce during the prenatal (or early postnatal) period, the developing body predicts that the future will also be nutritionally deprived. The body may then invoke (difficult-to-reverse) biological mechanisms to adapt to the predicted future environment. For example, the metabolic system may adapt in a manner that will allow the individual to survive in an environment with chronic food shortages. This pattern is termed the "thrifty phenotype" and is sometimes referred to as the Barker hypothesis. The "problem" arises if in fact there is not a long-run food shortage, and nutrition is plentiful. In that case, the early life metabolic adaptations are a bad match to the actual environment and will increase the likelihood that the individual develops a metabolic disorder, which can include high blood pressure (hypertension), type II diabetes, obesity, and cardiovascular disease. The negative consequences do not usually appear until after reproductive age, which is preferable to the species from an evolutionary perspective (Barker 1992). Note that both preand postnatal nutrition can drive this programming. ${ }^{6}$

Observational studies of the Dutch Hunger Winter yielded influential and supportive findings. At the end of World War II, the Nazis sharply restricted food shipments in the Netherlands over the seven-month period between November 1944 and April 1945. As a result, the previously well-nourished society experienced a severe decline in caloric availability from 1,800 calories per day to between 400 and 800. Upon liberation, the food supply returned to normal levels quickly. Painter, Roseboom, and Bleker (2005) find that children exposed to famine in the third trimester had birth weight and birth lengths about one-half of a standard deviation lower than a control group. ${ }^{7}$ Further, when the cohort that was exposed to malnutrition in utero reached middle age, they were more likely to be obese, and had higher incidence of heart disease, lower self-reported health status, and worse mental health (Painter, Roseboom, and Bleker 2005; Susser and Lin 1992). Although the period of malnutrition was short and abrupt relative to other famines, nonetheless the interpretation of these findings is subject to caveats due to the high rate of mortality during

\footnotetext{
${ }^{6}$ Much of the experimental work on nutritional programming has been conducted on rats. A canonical study, McCance (1962) experimentally reduced the amount of breast milk available to baby rats during their normal 21-day suckling period. At the end of the experiment, the treatment group was smaller than the control group, but quickly caught up to normal size when fed normal rations. In the longer run, however, the treatment group became more obese despite being fed the same amount as the control group. In a follow-up study, researchers found that if they manipulated the food intake for a different (later) 21-day period, there were no long-run effects suggesting a "critical period" for the effects.

${ }^{7}$ In a parallel manner, our earlier work (Almond, Hoynes, and Schanzenbach 2011) finds that infants have higher birth weight if exposed to food stamps in the third trimester.
} 
the famine (leading to selection in survival) and pretrends in famine measures such as death rates. ${ }^{8}$

To summarize, the literature has found that lack of nutrition in early life leads to higher incidence of metabolic syndrome. These impacts have occurred both when the nutritional shock occurred in utero and when it occurred in the period shortly after birth. Importantly, the long-run health outcomes have been found even in cases in which birth weight itself was not affected. Thus, the impacts of in utero shocks do not necessarily directly map into birth weight and evaluating the long-term impacts requires the analysis of a many-decade-past change, such as we do in this paper.

In our setting, we examine a policy-driven increase in economic resources to a population that had previously experienced chronic low levels of nutrition. Therefore, we expect that individuals who were exposed to the FSP program in early life will be less likely to have misadapted to the future environment and are predicted to have lower incidence of metabolic syndrome-as measured by high blood pressure, obesity, and diabetes - in adult life. We also expect to find better human capital outcomes, as measured by education, earnings, income, and the like. Because the literature is unclear about the exact timing of postnatal damage, we will explore alternative specifications for the timing of FSP exposure.

\section{Introduction of the Food Stamp Program}

Today, food stamp benefits are the fundamental safety net in the US, being the only public assistance program that is available to all family types (most programs are targeted on female-headed households, children, or the elderly). Eligibility requires satisfying income and asset tests, and benefits can be used to purchase most grocery store food goods. A family's benefit is equal to the difference between the federally defined maximum benefit level for a given family size and the amount that the family is deemed to be able to afford to pay for food on its own according to the benefits formula (essentially 30 percent of cash income, less some deductions). ${ }^{9}$

The roots of today's Food Stamp Program began with President Kennedy's 1961 announcement of a pilot food stamp program that was to be established in eight impoverished counties. The pilot programs were later expanded to 43 counties in 1962 and 1963. The success of these pilot programs led to the Food Stamp Act of 1964, which gave local areas the authority to start up the FSP in their county. As with the current FSP, the program was federally funded and benefits were redeemable at approved retail food stores. In the period following the passage of the Food Stamp Act, there was a steady stream of counties initiating Food Stamp Programs and Federal spending on the FSP more than doubled between 1967 and 1969 (from $\$ 115$ million to $\$ 250$ million). Support for a national FSP grew due to a public spotlight on hunger (Berry 1984). This interest culminated in passage of 1973

\footnotetext{
${ }^{8}$ Almond and Mazumder (2011) consider the effect of nutrition timing during pregnancy on later life outcomes, focusing on the Ramadan fast as an identification strategy and finding that children born with in utero exposure to the Ramadan fast experienced large increases in disability in adulthood. Because fasting during Ramadan is confined to daylight hours, the nutritional treatment is relatively mild compared to famine episodes. We discuss early life interventions below in Section IVC

${ }^{9} \mathrm{~A}$ recent restriction limits nonworking, nondisabled childless adults aged 18 to 49 (referred to as able bodied adults without dependents (ABAWD)) to three months of benefits within a three-year period (Hoynes and Schanzenbach forthcoming).
} 


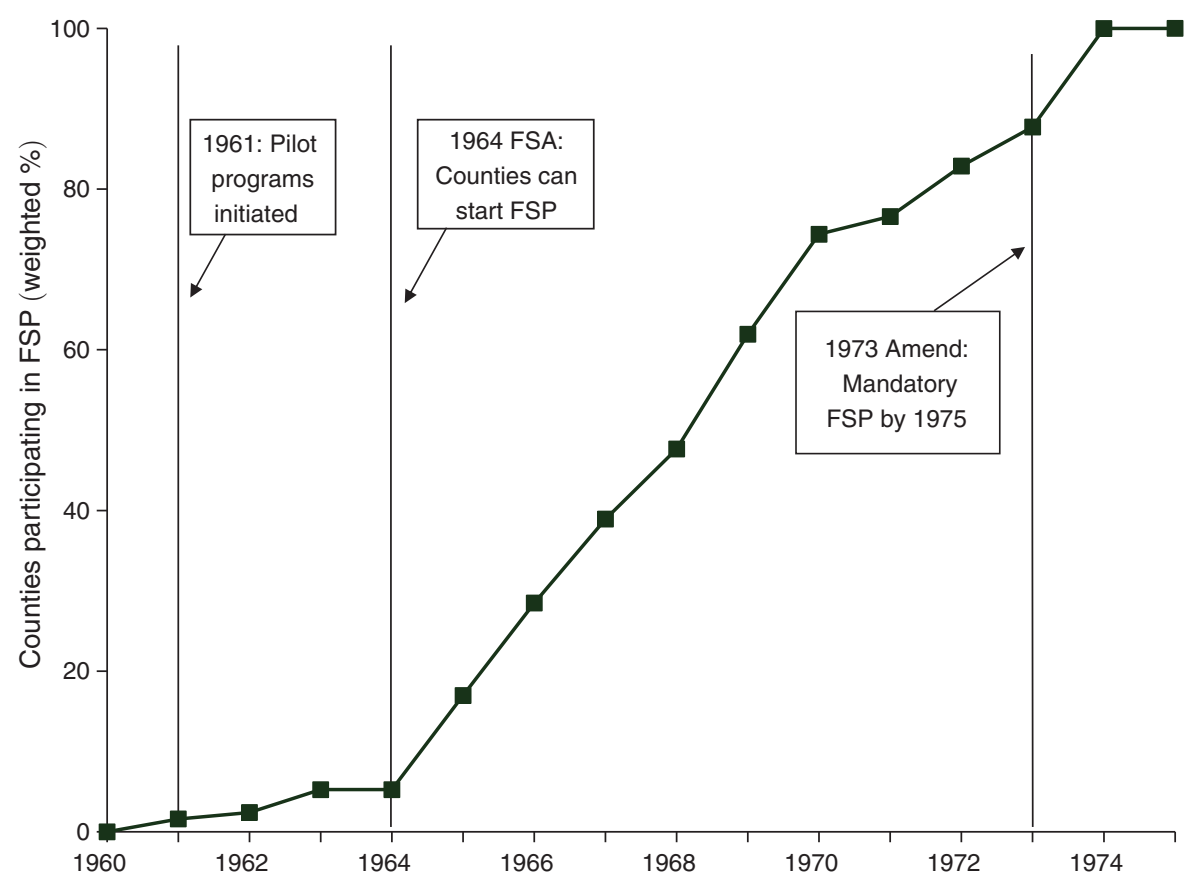

Figure 1. Weighted Percent of Counties with Food Stamp Program, 1960-1975

Source: Authors' tabulations of food stamp administrative data (US Department of Agriculture, various years). Counties are weighted by their 1960 population.

Amendments to the Food Stamp Act, which mandated that all counties offer FSP by 1975 .

Figure 1 plots the percent of counties with a FSP from 1960 to $1975 .{ }^{10}$ During the pilot phase (1961-1964), FSP coverage increased slowly. Beginning in 1964, program growth accelerated; coverage expanded at a steady pace until all counties were covered in 1974. Furthermore, there was substantial heterogeneity in timing of adoption of the FSP, both within and across states. The map in Figure 2 shades counties according to date of FSP adoption (darker shading denotes a later start-up date). Our basic identification strategy considers the month of FSP adoption for each county to trigger the beginning of the FSP "treatment."

For our identification strategy to yield causal estimates of the program, it is important to establish that the timing of FSP adoption appears to be exogenous and here we summarize what we have examined in our earlier work (Hoynes and Schanzenbach 2009). Prior to the FSP, some counties provided food aid through the commodity distribution program (CDP) which took surplus food purchased by the Federal government as part of an agricultural price support policy and distributed those goods to the poor. The 1964 Food Stamp Act allowed for counties to voluntarily set up a FSP,

\footnotetext{
${ }^{10}$ Counties are weighted by their 1970 population. Note this is not the food stamp caseload, but represents the percent of the US population that lived in a county with a FSP. Online Appendix Figure 1 reproduces this figure and adds the county-level coverage rate using the PSID data. The data available in the PSID line up well with the national rollout trends.
} 


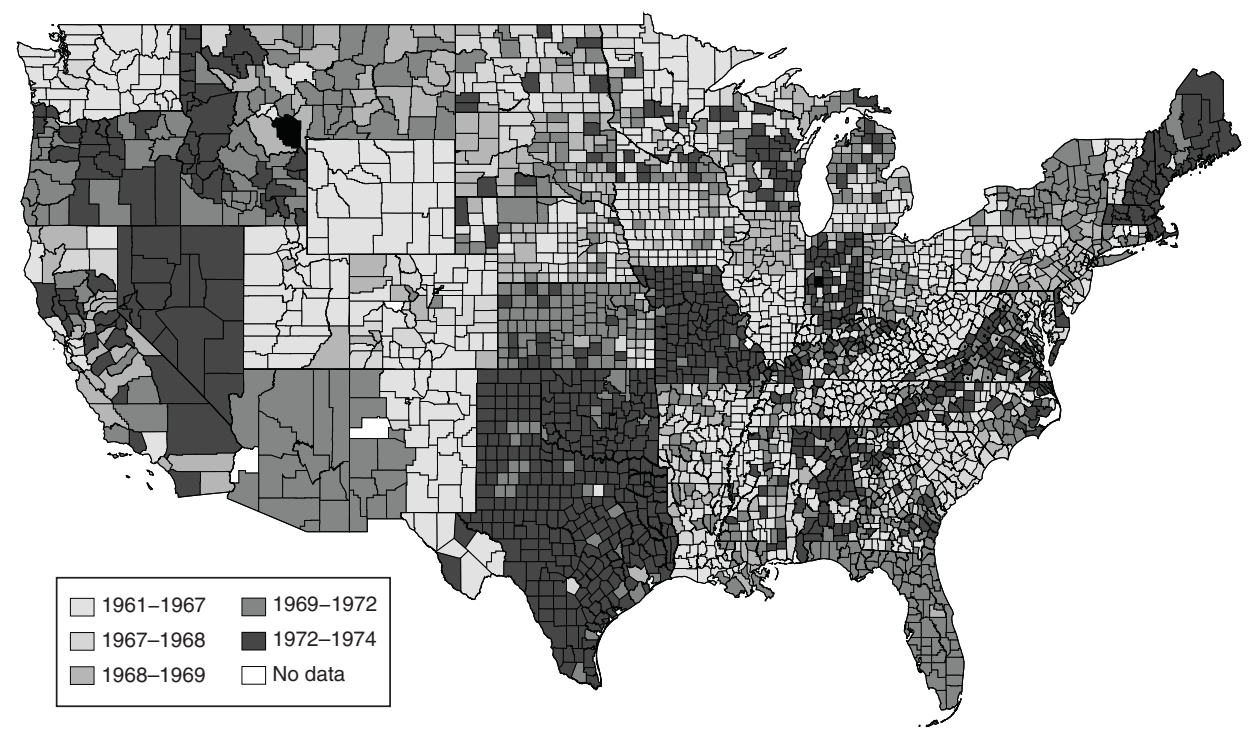

Figure 2. Food Stamp Program Start Date, by County, 1961-1974

Notes: Authors' tabulations of food stamp administrative data (US Department of Agriculture, various years). The shading corresponds to the county FSP start date, where darker shading indicates later county implementation.

but the Act also stated that no county could run both the FSP and the CDP. Thus, for counties which previously ran a CDP, adoption of the FSP implies termination of the CDP. ${ }^{11}$ The political accounts of the time suggest that debates about adopting the FSP pitted powerful agricultural interests (who favored the CDP) against advocates for the poor (who favored the FSP: see MacDonald 1977; Berry 1984). In particular, counties with strong support for farming interests (e.g., Southern or rural counties) may be late adopters of the FSP. On the other hand, counties with strong support for the low-income population (e.g., Northern, urban counties with large poor populations) may adopt FSP earlier in the period. This systematic variation in food stamp adoption could lead to spurious estimates of the program impact if those same county characteristics are associated with differential trends in the outcome variables.

In earlier work (Hoynes and Schanzenbach 2009), we documented that larger counties with a greater fraction of the population that was urban, black, or low income indeed implemented the FSP earlier (i.e., consistent with the historical accounts). ${ }^{12}$ Nevertheless, we found that the county characteristics explain very little of the variation in adoption dates. This is consistent with the characterization of funding limits controlling the movement of counties off the waiting list to start up

\footnotetext{
${ }^{11}$ This transition in nutritional assistance would tend to bias downward FSP impact estimates, but we do not think this bias is substantial because of the limited scope of the CDP. The CDP was not available in all counties and recipients often had to travel long distances to pick up the items. Further, the commodities were distributed infrequently and inconsistently, and provided a very narrow set of commodities - the most frequently available were flour, cornmeal, rice, dried milk, peanut butter, and rolled wheat (Citizens' Board of Inquiry 1968). In contrast, food stamp benefits can be used to purchase a wide range of grocery food items.

${ }^{12}$ For more detail, see Table 1 in Hoynes and Schanzenbach (2009).
} 
their FSP (Berry 1984). We view the weakness of this model fit as a strength when it comes to our identification approach in that much of the variation in the implementation of FSP appears to be idiosyncratic. Nonetheless, in order to control for possible differences in trends across counties that are spuriously correlated with the county treatment effect, all of our regressions include interactions of these 1960 pretreatment county characteristics with time trends as in Acemoglu, Autor, and Lyle (2004) and Hoynes and Schanzenbach (2009).

\section{Data}

Given the county rollout of the FSP, our analysis requires data with information on adult health and economic outcomes as well as county of birth for cohorts that were impacted by the FSP introduction (1963-1975) at birth or during early childhood. We use the Panel Study of Income Dynamics (PSID), which began in 1968 with a sample of approximately 5,000 households, and subsequently followed and interviewed all members and descendants. The original sample comprises two subsamples: a nationally representative sample of 3,000 households and the Survey of Economic Opportunity subsample including 1,900 low-income and minority households selected from an existing sample. To adjust for this nonrandom composition, we conduct all analysis using the PSID weights.

Since the beginning of the survey, the PSID has collected detailed information on economic and demographic outcomes. We use those data to generate adult economic outcomes such as educational attainment, employment, earnings, family income, and poverty. Starting in the 1980s and 1990s, the PSID also began regularly collecting information on health outcomes. We use self-reported general health status (reported on a 5-point scale: excellent, very good, etc.) and disability (physical or nervous condition that limits the type or amount of work), both of which have been asked of heads and wives each year beginning in 1984. In addition, the PSID respondents report height and weight (hence we can construct obesity ${ }^{13}$ and height stunting ${ }^{14}$ ), and information on whether a doctor has diagnosed the respondent with specific health conditions such as diabetes, high blood pressure, heart attack, and heart disease. ${ }^{15}$ These health data are collected for all heads and wives and have been available since 1999, when the survey became biennial. These data allow us to test for the prediction that the introduction of food stamps in early life leads to a reduction in the incidence of obesity, heart disease, and other components of metabolic syndrome. In addition, we use information on health behaviors including smoking, drinking, and exercise.

We use a restricted version of the PSID allowing for identification of county of residence for each year of the survey (the public-use version of the data only identifies state). Because of the longitudinal and dynastic nature of the data, for each individual, we can assign their county of residence at birth or, for those born prior to the

\footnotetext{
${ }^{13}$ Obesity is defined as having a body mass index (BMI, one's weight in kilograms divided by height in meters squared) of 30 and above.

${ }^{14}$ Height stunting is measured as being below the fifth percentile in the nationally normed height distribution (Lewit and Kerrebrock 1997). We use a gender-specific height distribution for 30-50-year olds in 2003-2006 reported in McDowell et al. (2008).

${ }^{15}$ Other health conditions measured in the PSID include stroke, arthritis, asthma, cancer, psychiatric problems, lung disease, and mental ability.
} 
beginning of PSID data collection, their county of residence in 1968 when their family is first observed in the data. We merge the PSID data to FSP program information based on this county of birth. The key variable for our analysis is constructed from the month and year that each county introduced the FSP, which we collected from USDA annual reports on county FSP caseloads (USDA, various years). With this, and using the month and year of birth (measured for each person in the survey), we construct measures of childhood exposure to the FSP. ${ }^{16}$ In our main specification, we use the share of time between conception and age five that FSP is available in county of birth. ${ }^{17}$

Our sample includes individuals born between the years 1956 and 1981. Importantly, this yields cohorts that span the entire food stamp rollout period (as well as several cohorts both pre- and post-rollout) to identify the impact on adult outcomes. In addition, we only include individuals whose family is observed at the individual's birth or in early life. ${ }^{18}$ This is necessary to identify the individual's county of birth. ${ }^{19}$ We also use information on the family background of the individual in early life (whether the child was born into a family headed by a single woman, education of head, and family income) as control variables and to identify groups more and less likely to participate in the FSP. We limit the sample to persons age 18 and older for the health outcomes and age 25 and older for the economic outcomes (to facilitate completed education). The sample includes one observation for each interview year that the individual satisfies these age restrictions, and is a head or spouse (recall that the health measures are only asked if a head or spouse). We use the PSID data through interview year $2009 .^{20}$ Thus, given our birth cohorts (1956-1981) the oldest individuals in our sample are 53 years old at the end of the period. We focus on a "high participation" sample, the sample of adults who grew up in disadvantaged families (their parent had less than a high school education).

We augment the PSID data with additional county variables to control for possible county confounders. First, we use county-level variables from the 1960 census of population and census of agriculture, including: the percent of the 1960 county population that lives in an urban area, is black, is younger than five, is older than 65 , has income less than $\$ 3,000$ (in 1959 US\$), the percent of land in the county used for farming, and log county population. Second, we measure for each county and year the number of hospital beds and hospitals per capita (from the American Hospital Association ${ }^{21}$ ), real (non-FSP) government transfers per capita (from the

\footnotetext{
${ }^{16}$ The geographic coverage of the PSID is quite good (especially given the modest sample size in the longitudinal survey). We find that about 60 percent of the population-weighted counties are captured by the sample. Online Appendix Figure 1 shows that the county rollout in the PSID matches well the pattern of the rollout based on all counties.

${ }^{17}$ We assume a nine-month gestation, so month of conception is nine months prior to birth month.

${ }^{18}$ In effect, this limits the sample to persons born into original 1968 PSID families.

${ }^{19}$ Because of the possibility of nonrandom migration, we calculate childhood exposure to the FSP using county of birth, rather than the time-varying county of residence.

${ }^{20}$ While sample attrition prior to 2009 is not insignificant (35 percent), we find that it is unrelated to the treatment variable. Summary statistics of the PSID sample look similar to nationally representative data from the Current Population Survey and National Health and Nutrition Examination Survey (with similar sample selection criteria).

${ }^{21}$ The American Hospital Association (AHA) data provide annual data that allows for us to measure county variables for the first five years of life for all birth cohorts (the Hospitals: Guide Issue publication goes back to 1948). We collapse the hospital-level data to county-year and then convert to per capita measures using historical
} 
Bureau of Economic Analysis Regional Economic Information System (REIS) ${ }^{22}$ ), and whether the county has a community health center. ${ }^{23}$ We use the AHA and REIS data and construct averages for the first five years of life (using county and year of birth). We use the community health center data to measure the share of months between conception and age five that there was a community health center present.

Table 1 presents descriptive statistics on our estimation sample. About 68 percent of the full sample and 58 percent of the high participation (parent low education) sample report to be in excellent or very good health. About 10 percent report a work disability and less than 5 percent are diabetic. Thirteen (19) percent of the full sample (low education subsample) has high blood pressure and 24 percent ( 32 percent) are obese.

\section{Empirical Model}

Our basic specification is a difference-in-differences model, where we compare adult outcomes for those with early childhood exposure to FSP in their county of birth to those born earlier (and therefore without childhood FSP exposure). We estimate

(1) $y_{i c b}=\alpha+\delta F S P_{c b}+X_{i c b} \beta+\eta_{c}+\lambda_{b}+\gamma_{t}+\theta_{s} \times b+\varphi C B 60_{c} \times b+\varepsilon_{i c b}$,

where $i$ indexes the individual, $c$ the county of birth, $b$ the birth year, $s$ the state of birth, and $t$ the survey year. FSP is a measure of food stamp availability in early life. In our base case models we measure the share of months between conception and age 5 that food stamps is available in the adult's birth county.

Because counties adopted FSP at different times, we compare those with or without FSP access in early childhood by virtue of their county and date of birth. Thus, we can allow for unrestricted cohort effects at the national level $\lambda_{b}$, unrestricted county effects $\eta_{c}$, unrestricted interview year effects $\gamma_{t}$, and state-specific linear year of birth trends $\theta_{s} \times b$. The parameter of interest is $\delta$, the effect of exposure to FSP, which is identified from variation within counties across birth cohorts. We also control for individual-level covariates $X_{i c b}$ (including gender, marital status, race, and a quadratic in age) and family background (whether you were born into a female-headed household, the education attainment of the head of household, and

county population data. We then prepare a simple average over the first five years of life. We thank Amy Finkelstein and Martin Gaynor for the pre-1976 data, Jean Roth of the NBER for the 1976 and on data, and Martha Bailey and Andrew Goodman-Bacon for providing code to clean the data.

${ }^{22}$ The REIS data are available for 1959 and 1962 and then annually beginning in 1965. We construct three measures for real per capita transfers that can be consistently measured throughout this period: cash public assistance benefits (Aid to Families with Dependent Children, Supplemental Security Income, and General Assistance), medical spending (Medicare and military health care), and cash retirement and disability payments (Social Security, Disability Insurance, other). We interpolate to fill in the gaps $(1960,1961,1963,1964)$. Analyses with these controls must drop birth cohorts before 1960 due to missing data.

${ }^{23}$ The information on community health centers provide the year that the first center established in a county, which occurred between 1965 and 1974 (Bailey and Goodman-Bacon 2015). We thank Martha Bailey and Andrew Goodman-Bacon for sharing this data. 
TABle 1 -Descriptive Statistics

\begin{tabular}{|c|c|c|c|c|}
\hline & \multicolumn{2}{|c|}{ Full sample } & \multicolumn{2}{|c|}{ High impact sample } \\
\hline & Observations & Mean & Observations & Mean \\
\hline FS share age IU-5 & 60,782 & 0.370 & 28,808 & 0.338 \\
\hline \multicolumn{5}{|l|}{ Health outcomes } \\
\hline Metabolic health index & 22,070 & -0.079 & 9,097 & 0.010 \\
\hline In good health $=1$ & 60,757 & 0.679 & 28,833 & 0.581 \\
\hline Disabled $=1$ & 60,753 & 0.096 & 28,827 & 0.118 \\
\hline Diabetes $=1$ & 22,546 & 0.041 & 9,321 & 0.054 \\
\hline High blood pressure $=1$ & 22,544 & 0.133 & 9,319 & 0.187 \\
\hline Obesity $=1$ & 24,127 & 0.240 & 10,209 & 0.322 \\
\hline Heart disease $=1$ & 22,543 & 0.019 & 9,320 & 0.028 \\
\hline Heart attack $=1$ & 22,548 & 0.006 & 9,323 & 0.008 \\
\hline Healthy weight $=1$ & 24,127 & 0.408 & 10,209 & 0.322 \\
\hline $\mathrm{BMI}$ & 24,127 & 26.862 & 10,209 & 28.255 \\
\hline Body weight (pounds) & 24,645 & 193.148 & 10,461 & 202.688 \\
\hline Height (inches) & 24,589 & 67.760 & 10,428 & 67.427 \\
\hline Height below 5 th percentile & 24,589 & 0.011 & 10,428 & 0.016 \\
\hline \multicolumn{5}{|l|}{ Economic outcomes } \\
\hline Economic outcome index & 57,585 & -0.051 & 27,303 & -0.304 \\
\hline Education high school plus & 60,106 & 0.903 & 28,663 & 0.786 \\
\hline $\log ($ total fam. income $)$ & 60,599 & 10.847 & 28,706 & 10.435 \\
\hline Earnings (including 0s) & 59,136 & 35,047 & 27,862 & 23,473 \\
\hline Employed $=1$ & 60,843 & 0.864 & 28,881 & 0.739 \\
\hline Poverty $=1$ & 60,599 & 0.184 & 28,706 & 0.339 \\
\hline Food stamp receipt & 60,665 & 0.085 & 28,759 & 0.157 \\
\hline TANF receipt & 60,839 & 0.033 & 28,873 & 0.061 \\
\hline \multicolumn{5}{|l|}{ Health behaviors } \\
\hline Ever smoked & 22,548 & 0.447 & 9,318 & 0.522 \\
\hline Drink $3+$ per day, now & 22,493 & 0.152 & 9,300 & 0.153 \\
\hline \multicolumn{5}{|l|}{ Demographics } \\
\hline Male & 60,898 & 0.462 & 28,905 & 0.442 \\
\hline Nonwhite & 60,777 & 0.171 & 28,823 & 0.317 \\
\hline High school grad. & 60,106 & 0.390 & 28,663 & 0.500 \\
\hline Greater than high school & 60,106 & 0.502 & 28,663 & 0.286 \\
\hline Age & 60,898 & 32.135 & 28,905 & 32.126 \\
\hline Married & 60,897 & 0.585 & 28,904 & 0.542 \\
\hline \multicolumn{5}{|l|}{ Family background } \\
\hline Female-headed household & 60,898 & 0.094 & 28,905 & 0.161 \\
\hline Income to needs ratio (5-year average) & 60,898 & 2.365 & 28,905 & 1.512 \\
\hline Head less than high school education & 60,496 & 0.345 & 28,905 & 1.000 \\
\hline \multicolumn{5}{|l|}{1960 county characteristics } \\
\hline Population & 60,882 & 593,051 & 28,905 & 514,635 \\
\hline Fraction of land, farmland & 60,882 & 48.4 & 28,905 & 49.4 \\
\hline Fraction of population, urban & 60,882 & 67.0 & 28,905 & 61.4 \\
\hline Fraction of population, black & 60,882 & 9.6 & 28,905 & 13.8 \\
\hline Retirement transfers per capita, $0-5$ average & 48,009 & 928.29 & 21,984 & 876.26 \\
\hline Medical transfers per capita, $0-5$ average & 47,568 & 149.71 & 21,661 & 125.15 \\
\hline Other public assistance per capita, $0-5$ average & 47,568 & 195.03 & 21,661 & 194.66 \\
\hline Number of hospital beds, $0-5$ average & 58,098 & 4.608 & 27,274 & 4.494 \\
\hline Number of hospitals, $0-5$ average & 58,098 & 0.036 & 27,274 & 0.040 \\
\hline Presence of Community Health Center, age $0-5$ average & 60,898 & 0.100 & 28,905 & 0.073 \\
\hline
\end{tabular}

Notes: Author's tabulations of 1968-2009 PSID. Sample consists of heads and wives born between 1956 and 1981. Observations from Alaska are dropped because of missing data on Food Stamp Program start date. See text for details on sample selection. 
the family's income to needs ratio). ${ }^{24}$ All models are estimated using the PSID sample weights and we cluster standard errors by county of birth. ${ }^{25}$

Because of the many outcome variables, we follow Kling, Liebman, and Katz (2007) and Anderson (2008) and estimate summary standardized indices that aggregate information over multiple treatments. In particular, we form two indices: metabolic syndrome and economic self-sufficiency. As discussed by Kling, Liebman, and Katz (2007), aggregating multiple measures in a given area (e.g., metabolic syndrome) improves statistical power. The summary index is the simple average across standardized $z$-score measures of each component. The $z$-score is calculated by subtracting the mean and dividing by the standard deviation. ${ }^{26}$ In the case of metabolic syndrome, all components are "bads" (obesity, high blood pressure, diabetes, heart disease, heart attack) and an increase in metabolic syndrome index indicates a worse outcome. For economic self-sufficiency, we convert each component of the index so that a higher score is a better outcome (e.g., convert "poor" to "not poor"). Economic self-sufficiency includes seven measures: high school graduate, employed, not poor, not on TANF, not on food stamps, earnings, and family income. ${ }^{27}$

The validity of our design depends on the exogeneity of the introduction of the FSP across counties. We address this in two ways. First, following Hoynes and Schanzenbach (2009), we control for trends in the observable determinants of FSP adoption by including interactions between characteristics of the county of birth and linear trends in year of birth $\left(C B 60_{c} \times b\right)$. Further, this period of FSP introduction took place during a period of tremendous expansion in cash and noncash transfer programs as part of the War on Poverty and Great Society. To explore these possible confounders, we directly control for several characteristics of county of birth (community health centers, hospitals and hospital beds per capita, and non-FSP government transfers per capita), measured as averages over the first five years of life.

The basic identification strategy underpinning equation (1) is different from many previous design-based studies in the fetal origins literature. Typically, natural experiments induced by famines, disease outbreaks, etc., are episodic: they turn on and then turn off. In contrast, once the FSP starts operating in a given county, it keeps operating and does not "turn off." An analysis of short-term impacts of the policy, such as maternal exposure and impacts on birth weight (as in Almond, Hoynes, and Schanzenbach 2011), leads to a 0/1 treatment variable for "FSP introduction." However, in the current setting, we have a much longer period of potential exposure (through childhood). This restricts the set of cohort comparisons that can be made. For example, we will never observe a birth cohort exposed in early childhood (e.g., up to age five), but without exposure in later childhood (after age five). Instead, comparisons are "from above": we observe cohorts with the addition of exposure prior to age five, but this comes on top of exposure at older ages. So, comparisons are inherently about additional FSP

\footnotetext{
${ }^{24}$ These family background measures are averages over the first five years of life, or in the case of the cohorts born prior to the beginning of the PSID, the first five years of sample.

${ }^{25}$ The significance of results are robust to including dynastic family fixed effects and clustering instead by dynastic family.

${ }^{26}$ Kling, Liebman, and Katz (2007) analyze a randomized experiment and use the control group mean and standard deviation in calculating the $z$-score. In our quasi-experimental design, we mimic this approach by using the mean and standard deviation of the cohorts born before food stamp rollout began (cohorts born before 1961).

${ }^{27}$ The top-coding of earnings and income changes over the course of the survey. We trim the sample and drop those (relative few observations) with earnings or income in excess of $\$ 300,000$.
} 
exposure earlier in childhood, conditional on having it later in childhood. To illustrate the variation we have, online Appendix Figure 2 shows average FSP exposure by birth cohort for three measures of food stamp availability: in utero, share of months between birth and age five, and share of months between 6 and age 18 .

\section{Results}

\section{A. High Participation Sample}

We begin with our "high participation" sample, adults born between 1956 and 1981 who grew up in disadvantaged families (i.e., their parent had less than a high school education). Table 2 presents estimates for metabolic syndrome for the high participation sample. We define FSP exposure as the share of months between conception and age five that the FSP was available in the individual's county of birth (FS share IU-5 in the table). The "metabolic syndrome index" is the equal weighted average of the $z$-score of five dichotomous variables: obese, diabetic, high blood pressure, heart disease, and heart attack. This, and all subsequent specifications, includes individual demographics, family background controls, and fixed effects for year of birth, year of interview, county, state linear trends (in cohort), and 1960 county characteristics linear cohort trends. The effect of access to food stamps in childhood on metabolic syndrome, as shown in column 1, is -0.294 and is statistically significant at the 1 percent level. The magnitude of the coefficient implies that increasing the share from zero to 1 (from no exposure to full exposure in utero to age five) reduces metabolic syndrome by 0.3 standard deviations.

The remaining columns of Table 2 show the regressions for the individual components of metabolic syndrome index. While individually only obesity reaches statistical significance, each of the point estimates indicate an improvement in adult health with the food stamp treatment in childhood. To test whether the improvements on the other components of metabolic syndrome are mediated through the reduction in obesity, we reestimated the metabolic syndrome index excluding obesity, including and excluding direct controls for obesity. Doing so changed the estimated impact of FSP on the adjusted index very little, suggesting the other health improvements are not merely resulting from a decline in obesity. To further understand mechanisms, we also explored how the impacts of the FSP on metabolic syndrome (or obesity) change if we control for adult health behaviors such as smoking, alcohol consumption, and exercise. The estimated impacts of FSP exposure were little changed when these additional (potentially endogenous) variables were controlled, providing support for the Barker hypothesis and not pointing to behavioral changes as the mechanism. ${ }^{28}$ Results are available in online Appendix Tables 1-3.

The estimates in Table 2 are intent-to-treat estimates, averaging across persons with higher and lower likelihoods of being affected by food stamps. ${ }^{29}$ Of course,

\footnotetext{
${ }^{28}$ We also explored including direct controls for birth weight, and the results are also little changed. Birth weight measures are very incomplete for these cohorts of the PSID, though, with one-half of the sample having missing data or only a binary indicator for whether birth weight was above 5.5 pounds.

${ }^{29}$ This is a reduced-form model, rather than an instrumental variables (IV) approach with the FSP rollout instrumenting for the household's FSP participation. We do not estimate the IV because participation is measured only beginning in 1968, the first year of the PSID survey.
} 
Table 2-Metabolic Syndrome Index for High Participation Sample

\begin{tabular}{lcccccc}
\hline \hline & & \multicolumn{4}{c}{ Components of metabolic syndrome index } \\
\cline { 3 - 7 } & $\begin{array}{c}\text { Metabolic } \\
\text { syndrome (index) }\end{array}$ & Diabetes & $\begin{array}{c}\text { High blood } \\
\text { pressure }\end{array}$ & Obesity & $\begin{array}{c}\text { Heart } \\
\text { disease }\end{array}$ & $\begin{array}{c}\text { Heart } \\
\text { attack }\end{array}$ \\
\hline FS share IU-5 & $\begin{array}{c}-0.294^{* * *} \\
(0.107)\end{array}$ & $\begin{array}{c}-0.032 \\
(0.048)\end{array}$ & $\begin{array}{c}-0.13 \\
(0.086)\end{array}$ & $\begin{array}{c}-0.159 * \\
(0.086)\end{array}$ & $\begin{array}{c}-0.053 \\
(0.027)\end{array}$ & $\begin{array}{c}-0.031 \\
(0.019)\end{array}$ \\
Mean of dependent variable & 0.01 & 0.05 & 0.19 & 0.33 & 0.03 & 0.01 \\
Observations & 8,246 & 8,431 & 8,430 & 9,217 & 8,430 & 8,432 \\
$R^{2}$ & 0.26 & 0.19 & 0.22 & 0.26 & 0.13 & 0.08 \\
\hline
\end{tabular}

Notes: Each parameter is from a separate regression of the outcome variable on FSP exposure (share of months between conception and age five that FSP is in the county). The sample comes from the 1968-2009 PSID and includes heads and wives born between 1956 and 1981 who are between 18 and 53 (or 24-53 for economic outcomes). The high participation sample includes those born into families where the head had less than a high school education. Estimates are weighted using the PSID weights and clustered on county of birth. The models control for individual demographics, family background, and fixed effects for year of birth, year of interview, county, state-specific linear cohort, and 1960 county characteristics interacted with linear cohort. Standard errors are in parentheses.

*** Significant at the 1 percent level.

** Significant at the 5 percent level.

* Significant at the 10 percent level.

the food stamp participation rate is not 100 percent, even in this high participation sample. We estimate that for families where heads have less than a high school degree, 43 percent participate in food stamps at some point in their child's life. Thus, to convert these estimates to the treatment on the treated, one should divide the treatment effects by $0.43 .^{30}$

Table 3 presents estimates for other health outcomes for the high participation sample. Column 1 presents results for being in "good health" defined as one if the individual reports being in excellent or very good health (as opposed to good, fair, or poor health). The coefficient equals 0.11 , which implies that going to full exposure between conception and age five leads to an 11-percentage-point increase compared to a mean of 59 percent, though this is not statistically significant. Column 2 presents estimates for a work-limiting disability and while the coefficient is negative (i.e., an improvement as expected) it is very small and statistically insignificant. ${ }^{31}$ The third column indicates that access to the FSP leads to a reduction in the risk of stunting (height below the fifth percentile of the nationally normed distribution). ${ }^{32}$ The final two columns of the table present results for health behaviors: dichotomous variables for whether the person ever smoked and whether they drink 3 or more drinks per day (now). Both suggest an improvement but neither is statistically significant.

\footnotetext{
${ }^{30}$ It is the participation rate of the sample individuals at birth and in early life that is relevant, rather than their contemporaneous (adult) participation rate. To calculate the 0.43 FSP participation rate, we calculate the share of families with children who ever report receiving food stamps (in the period when they have children in the household). We limit the sample to 1978 and later, after the FSP has been rolled out in all counties.

${ }^{31}$ Note that the sample size for health status and disability are substantially larger than those in Table 2 because these questions have been included in the survey since 1984 .

${ }^{32}$ Table 3 shows that the mean of the stunting measure is below 0.05 which is consistent with the results in Andreski, McGonagle, and Schoeni (2009) finding that the height measures in the PSID are somewhat higher than in other health surveys. The qualitative results are the same if we define stunting as below the tenth percentile. In results not reported here, we also investigated whether availability of food stamps during more refined age categories reduced stunting, consistent with Case and Paxson's (2008) finding of some "catch-up" growth during puberty. The results in the PSID were inconsistent and imprecise.
} 
Table 3-Additional Health Outcomes for the High Participation Sample

\begin{tabular}{lccccccc}
\hline \hline & \multicolumn{3}{c}{ Other health outcomes } & & \multicolumn{2}{c}{ Health behaviors } \\
\cline { 2 - 3 } \cline { 7 - 7 } & In good health & Disabled & $\begin{array}{c}\text { Height below } \\
\text { 5th percentile }\end{array}$ & & Ever smoked & $\begin{array}{c}\text { Drink 3+ } \\
\text { day now }\end{array}$ \\
\hline FS share IU-5 & 0.110 & -0.004 & $-0.060^{* *}$ & & -0.078 & -0.002 \\
& $(0.074)$ & $(0.039)$ & $(0.026)$ & & $(0.131)$ & $(0.052)$ \\
$Y$-mean & 0.59 & 0.12 & 0.02 & & 0.52 & 0.15 \\
Observations & 25,738 & 25,731 & 9,398 & & 8,430 & 8,413 \\
$R^{2}$ & 0.16 & 0.13 & 0.22 & & 0.32 & 0.25 \\
\hline
\end{tabular}

Notes: Each parameter is from a separate regression of the outcome variable on FSP exposure (share of months between conception and age five that FSP is in the county). The sample comes from the 1968-2009 PSID and includes heads and wives born between 1956 and 1981 who are between 18 and 53 years old (or 24-53 for economic outcomes). The high participation sample includes those born into families where the head had less than a high school education. Estimates are weighted using the PSID weights and clustered on county of birth. The models control for individual demographics, family background, and fixed effects for year of birth, year of interview, county, state-specific linear cohort, and 1960 county characteristics interacted with linear cohort. Standard errors are in parentheses.

*** Significant at the 1 percent level.

** Significant at the 5 percent level.

* Significant at the 10 percent level.

Table 4-Economic Self-Sufficiency in the High Participation Sample

\begin{tabular}{|c|c|c|c|c|c|c|c|c|}
\hline & \multirow[b]{2}{*}{$\begin{array}{l}\text { Economic } \\
\text { self sufficiency } \\
\quad(\text { index })\end{array}$} & \multicolumn{7}{|c|}{ Components of economic self-sufficiency index } \\
\hline & & $\begin{array}{l}\text { High } \\
\text { school } \\
\text { plus }\end{array}$ & Not poor & $\begin{array}{c}\text { Not } \\
\text { on food } \\
\text { stamps }\end{array}$ & $\begin{array}{l}\text { Not on } \\
\text { TANF }\end{array}$ & Employed & Earnings & $\begin{array}{c}\log (\text { family } \\
\text { income })\end{array}$ \\
\hline FS share IU-5 & $\begin{array}{c}0.182 \\
(0.124)\end{array}$ & $\begin{array}{c}0.184 * \\
(0.108)\end{array}$ & $\begin{array}{c}0.052 \\
(0.067)\end{array}$ & $\begin{array}{c}0.032 \\
(0.052)\end{array}$ & $\begin{array}{c}0.023 \\
(0.026)\end{array}$ & $\begin{array}{c}-0.007 \\
(0.056)\end{array}$ & $\begin{array}{c}3,610 \\
(5,064)\end{array}$ & $\begin{array}{c}0.247 \\
(0.165)\end{array}$ \\
\hline$Y$-mean & -0.25 & 0.80 & 0.70 & 0.86 & 0.95 & 0.76 & 24,495 & 10.52 \\
\hline Observations & 20,115 & 21,197 & 21,209 & 20,115 & 21,347 & 21,348 & 20,529 & 21,160 \\
\hline$R^{2}$ & 0.38 & 0.29 & 0.30 & 0.38 & 0.16 & 0.18 & 0.34 & 0.37 \\
\hline
\end{tabular}

Notes: Each parameter is from a separate regression of the outcome variable on FSP exposure (share of months between conception and age five that FSP is in the county). The sample comes from the 1968-2009 PSID and includes heads and wives born between 1956 and 1981 who are between ages 18 and 53 (or 24-53 for economic outcomes). The high participation sample includes those born into families where the head had less than a high school education. Estimates are weighted using PSID weights and clustered on county of birth. The models control for individual demographics, family background, and fixed effects for year of birth, year of interview, county, state-specific linear cohort, and 1960 county characteristics interacted with linear cohort. Standard errors in parentheses.

*** Significant at the 1 percent level.

** Significant at the 5 percent level.

* Significant at the 10 percent level.

We go on to analyze the economic outcomes for the high participation sample in Table 4. The first column presents estimates for the "economic self-sufficiency index." This is an equal weighted average of seven items where, for each, the variables are converted (if needed) such that an increase in the outcome represents a better outcome. The components are: educational attainment is high school or higher, not poor, not on food stamps, not on TANF, employed, earnings, and the log 
of family income. ${ }^{33}$ The coefficient on the food stamp treatment is 0.182 , implying that full FSP access to age five leads to a 0.2 standard deviation improvement in economic self-sufficiency ( $p$-value is 0.14 ). The remainder of the columns provide the estimates for the individual components of the economic self-sufficiency index. All coefficients with the exception of employment status suggest that exposure to food stamps leads to an improvement in later life economic well-being: increases in education, earnings, and income and a reduction in poverty and participation in public assistance programs. However, only the coefficient on educational attainment reaches statistical significance.

Interestingly, the interpretation of the coefficient on adult food stamp receipt (column 4 of Table 4) is potentially more complicated than the biological theories discussed above. Observational data show a relatively strong degree of intergenerational transmission of "welfare use" (Bane and Ellwood 1994). Obtaining causal estimates for intergeneration transmission is difficult, however, given the strong persistence in other factors associated with economic success. ${ }^{34}$ In any case, the intergeneration transmission story would imply a positive effect of exposure to food stamps in early life on adult participation in the program. While the results here are not conclusive given the lack of precision in the estimate, the point estimate (positive on not participating in food stamps) suggests that on net the improvement in skills dominates any intergenerational transmission of welfare use.

In Table 5 we present the main results in the high participation sample by gender of the adult. ${ }^{35}$ We find quite striking evidence that the effects for economic self-sufficiency vary by gender, with large and statistically significant impacts for women, but very small and insignificant results for men. This is consistent with the several studies that find larger economic impacts of postnatal, early life interventions among girls (Anderson 2008; Bleakley 2007; Dahl and Lochner 2012; Field, Robles, and Torero 2009; Kling, Liebman, and Katz 2007; Maccini and Yang 2009; Milligan and Stabile 2011). The estimates for the effect of food stamps on metabolic syndrome are significant for both groups, but larger for men than for women. The larger effects for men are consistent with the long-term health impacts of randomized trials on high-quality early childcare (Campbell et al. 2014) and of nutritional supplementation in Guatemala (Stein et al. 2006), and also with the biological evidence that males are more subject to harm in utero than females (Almond and Currie 2011a). ${ }^{36}$ Interestingly, the gender differences in self-reported health status show a different pattern, with significant positive effects concentrated among women. In interpreting these gender differences, it is important to point out that there is no evidence that prenatal exposure to food stamps affects number of live births or infant mortality, overall or by gender (Almond,

\footnotetext{
${ }^{33}$ Note that in Table 4, the mean of the self-sufficiency index is not zero. As described above, we use the full sample of individuals born before 1962 to create the $z$-scores of each component. The mean here is lower due to our "high participation" subsample (which is lower socioeconomic status) and due to our sample being younger (and thus lower earnings etc.) than the pre-1962 sample.

${ }^{34}$ Dahl, Kostøl, and Mogstad (2014) find causal evidence from Norway that the adult children of parents who receive disability insurance are also more likely to participate in the program.

${ }^{35}$ Table 5 shows that we have more women in our sample than men which is a result of the fact that our sample includes individuals in survey years when they are a head or spouse. This gender imbalance is known and has been documented by Andreski, McGonagle, and Schoeni (2009).

${ }^{36}$ Males tend to suffer higher mortality rates in response to adverse events than females. In addition to higher mortality, males could also exhibit larger long-term effects if males suffer a more pronounced (unobserved) health shock than females in response to the same event (e.g., food stamps).
} 
Table 5-Metabolic Syndrome and Economic Self-Sufficiency in the High Participation Sample, BY GENDER

\begin{tabular}{|c|c|c|c|c|c|c|}
\hline & \multicolumn{3}{|c|}{ Women } & \multicolumn{3}{|c|}{ Men } \\
\hline & $\begin{array}{c}\text { Metabolic } \\
\text { syndrome } \\
\text { (index) }\end{array}$ & $\begin{array}{l}\text { Good } \\
\text { health }\end{array}$ & $\begin{array}{c}\text { Economic } \\
\text { self-sufficien- } \\
\text { cy (index) }\end{array}$ & $\begin{array}{c}\text { Metabolic } \\
\text { syndrome } \\
\text { (index) }\end{array}$ & $\begin{array}{l}\text { Good } \\
\text { health }\end{array}$ & $\begin{array}{c}\text { Economic } \\
\text { self-sufficien- } \\
\text { cy (index) }\end{array}$ \\
\hline FS share IU-5 & $\begin{array}{c}-0.312 * * \\
(0.130)\end{array}$ & $\begin{array}{l}0.336 \text { *** } \\
(0.100)\end{array}$ & $\begin{array}{c}0.306^{*} \\
(0.164)\end{array}$ & $\begin{array}{c}-0.526^{* *} \\
(0.251)\end{array}$ & $\begin{array}{c}-0.077 \\
(0.112)\end{array}$ & $\begin{array}{c}0.005 \\
(0.168)\end{array}$ \\
\hline Mean of dependent variable & 0.03 & 0.53 & -0.37 & -0.01 & 0.66 & -0.11 \\
\hline Observations & 5,062 & 15,702 & 12,208 & 3,184 & 10,036 & 7,907 \\
\hline$R^{2}$ & 0.37 & 0.22 & 0.43 & 0.32 & 0.18 & 0.46 \\
\hline
\end{tabular}

Notes: Each parameter is from a separate regression of the outcome variable on FSP exposure (share of months between conception and age five that FSP is in the county). The sample comes from the 1968-2009 PSID and includes heads and wives born between 1956 and 1981 who are between ages 18 and 53 (or 24-53 for economic outcomes). The high participation sample includes those born into families where the head had less than a high school education. Estimates are weighted using PSID weights and clustered on county of birth. The models control for individual demographics, family background, and fixed effects for year of birth, year of interview, county, state-specific linear cohort, and 1960 county characteristics interacted with linear cohort. Standard errors in parentheses.

*** Significant at the 1 percent level.

** Significant at the 5 percent level.

* Significant at the 10 percent level.

Hoynes, and Schanzenbach 2011); such an effect, if present, would suggest selective mortality and cloud the interpretation of these results. ${ }^{37}$

Identification in the model comes from variation in food stamp rollout across counties and birth cohorts. Importantly, the Food Stamp Program was expanded in the midst of the Great Society, a time when many health and human capital programs were expanding across the United States. Much of that policy variation resulted from state rather than county implementation. However, in Table 6. we examine the sensitivity of our core health and economics outcomes to adding controls for county programs and resources available between ages zero and five. The first three columns examine metabolic syndrome, where the first column repeats the main estimates from column 1 of Table 2. In the second column we add controls for access to health care resources (hospitals per capita, hospital beds per capita, presence of community health centers). In the third column we add controls for real per capita government transfers. ${ }^{38}$ We then repeat the three specifications for the economic self-sufficiency index in columns 4 to 6 . The table shows that our results are highly robust to adding these controls. ${ }^{39}$

An additional test for the validity of the design is to estimate the model by limiting the sample to those who are unlikely to have been impacted by the program. In Table 7, we employ this placebo test and limit to only those individuals from families with

\footnotetext{
${ }^{37}$ Aside from biological factors, it is possible that postnatal treatment differs between girls and boys, and that this might change with food stamp treatment. Interestingly, Lhila and Simon (2008) find that families with girls are more likely to take up the WIC nutrition program postnatally.

${ }^{38}$ The number of observations declines when we add the county controls for government per capita transfers. This is because the REIS data begin in 1959 and we therefore have to drop all observations with a year of birth 1958 or earlier.

${ }^{39}$ We also control for county-level birth year infant mortality rates in supplemental specifications (see online Appendix Table 4). Including this variable makes only a small difference in the coefficient size, but we do not include it in our main specification because of endogeneity concerns.
} 
Table 6-Metabolic Syndrome and Economic Self-Sufficiency in the High Participation Sample, AdDing County Controls

\begin{tabular}{|c|c|c|c|c|c|c|}
\hline \multirow[b]{2}{*}{ FS share IU-5 } & \multicolumn{3}{|c|}{ Metabolic syndrome (index) } & \multicolumn{3}{|c|}{ Economic self-sufficiency (index) } \\
\hline & $\begin{array}{c}-0.294 * * * \\
(0.107)\end{array}$ & $\begin{array}{c}-0.200 * * \\
(0.079)\end{array}$ & $\begin{array}{c}-0.209 * * \\
(0.081)\end{array}$ & $\begin{array}{c}0.182 \\
(0.124)\end{array}$ & $\begin{array}{c}0.171 \\
(0.125)\end{array}$ & $\begin{array}{c}0.210 \\
(0.150)\end{array}$ \\
\hline$Y$-mean & 0.01 & 0.01 & -0.02 & -0.25 & -0.27 & -0.26 \\
\hline Observations & 8,246 & 7,737 & 6,561 & 20,115 & 18,992 & 13,268 \\
\hline$R^{2}$ & 0.26 & 0.27 & 0.26 & 0.38 & 0.38 & 0.37 \\
\hline $\begin{array}{l}\text { Hospitals, beds per capita } \\
\text { Community health center } \\
\text { REIS real per capita transfers }\end{array}$ & & $\begin{array}{l}X \\
X\end{array}$ & $\begin{array}{l}X \\
X \\
X\end{array}$ & & $\begin{array}{l}X \\
X\end{array}$ & $\begin{array}{l}X \\
X \\
X\end{array}$ \\
\hline
\end{tabular}

Notes: Each parameter is from a separate regression of the outcome variable on FSP exposure (share of months between conception and age five that FSP is in the county). The sample comes from the 1968-2009 PSID and includes heads and wives born between 1956 and 1981 who are between 18 and 53 years old (or 24-53 for economic outcomes). The high participation sample includes those born into families where the head had less than a high school education. Estimates are weighted using the PSID weights and clustered on county of birth. The models control for individual demographics, family background, and fixed effects for year of birth, year of interview, county, state-specific linear cohort, and 1960 county characteristics interacted with linear cohort. The additional county controls are annual averages from birth to age five. Standard errors are in parentheses.

*** Significant at the 1 percent level.

** Significant at the 5 percent level.

* Significant at the 10 percent level.

high levels of head's education (more than a high school education). These results show small, imprecise, and generally wrong-signed impacts for both health and economic outcomes. In online Appendix Table 5 we extend this analysis and estimate the metabolic syndrome model for more subgroups, finding larger effects of food stamps on more disadvantaged groups including nonwhites and children growing up with single parents. Overall, these results add support to our approach.

Another concern may be that our high participation sample is too broad, and may include substantial shares of individuals who do not participate in the program or are not malnourished. A different approach, which we take in Table 8, is to limit the analysis to individuals living in counties with high levels of deprivation. The first column provides our base results for metabolic syndrome. Columns 2 and 3 use information on county-level "hunger deaths" (ICD code "malnutrition unqualified") measured in 1962 and 1963, stratifying based on hunger deaths as a fraction of the total population (column 2) and hunger deaths as a fraction of all deaths (column 3 ). In column 4 we stratify on infant mortality rates for deaths that could be related to nutritional deficiencies. ${ }^{40}$ In column 5 , we stratify by the 1960 county-level poverty rate. Panel A limits the analysis to the most disadvantaged quartile of counties (population weighted) as measured by each of these characteristics and panel B limits to counties in the lowest quartile of each measure: i.e., the least disadvantaged counties. The point estimates show that our main finding is concentrated in the most disadvantaged counties with consistently smaller impacts in the more advantaged

\footnotetext{
40 "Hunger deaths" are rare (about 1,400 per year in this period) and are identified by the one ICD code. Nutrition-related deaths capture a much broader set of cause of death conditions. See Almond, Hoynes, and Schanzenbach (2011) for a discussion of these variables and their definitions.
} 
Table 7-Metabolic Syndrome and Economic Self-Sufficiency for High Education Group (Placebo Test)

\begin{tabular}{lcc}
\hline \hline & Metabolic syndrome (index) & $\begin{array}{c}\text { Economic self-sufficiency } \\
\text { (index) }\end{array}$ \\
\hline FS share IU-5 & -0.013 & 0.073 \\
& $(0.060)$ & $(0.087)$ \\
$Y$-mean & -0.17 & 0.22 \\
& & \\
Observations & 5,398 & 10,180 \\
$R^{2}$ & 0.24 & 0.33 \\
& obesity, high blood pressure \\
"Right" signed components & $\begin{array}{c}\text { good health, disability, } \\
\text { diabetes, heart disease }\end{array}$ & $\begin{array}{c}\text { education, family income, } \\
\text { food stamps }\end{array}$ \\
\hline
\end{tabular}

Notes: Each parameter is from a separate regression of the outcome variable on FSP exposure (share of months between conception and age five that FSP is in the county). The sample comes from the 1968-2009 PSID and includes heads and wives born between 1956 and 1981 who are between 18 and 53 years old (or 24-53 for economic outcomes). The sample includes those born into families where the head had a high school education or more. Estimates are weighted using the PSID weights and clustered on county of birth. The models control for individual demographics, family background, and fixed effects for year of birth, year of interview, county, state-specific linear cohort, and 1960 county characteristics interacted with linear cohort. Standard errors are in parentheses.

*** Significant at the 1 percent level.

** Significant at the 5 percent level.

* Significant at the 10 percent level.

counties. While imprecisely estimated, we take these results as further support for our findings.

\section{B. Full Sample Triple Difference}

In choosing our preferred sample for this analysis, we face a trade-off between sample size (using the full sample of adults) and targeting (using the smaller, more targeted samples). Building on the findings for the high participation sample, here we use the full sample of adults in our PSID sample, but use a triple-difference specification that accounts for different probabilities of being affected by food stamps. In particular, we augment model (1) above and estimate

$$
\begin{aligned}
y_{i c b}= & \alpha+\varphi F S P_{c b}+\delta F S P_{c b} P_{g}+X_{i c b} \beta+\eta_{c} \\
& +\lambda_{b}+\gamma_{t}+\mu_{g}+\theta_{s} \times b+\varphi C B 60_{c} \times b+\varepsilon_{i c b} .
\end{aligned}
$$

To capture the varying risks of being treated we multiply the FSP treatment by a group-level food stamp participation rate (Bleakley 2007; Hoynes and Schanzenbach 2009). The group food stamp participation rate $P_{g}$ is defined for 12 groups using education $(<12,12,>12)$, race (white, nonwhite), and marital status (married, not married) based on the family background of the adult (e.g., their parents' characteristics). We calculate the participation rate in the same fashion as discussed above (to convert intent-to-treat to treatment-on-treated). In addition to the variables in the model (1), we add a main effect for food stamp treatment, fixed effects for 
Table 8-Metabolic Syndrome Index for High Participation Sample, Stratify on Pretreatment COUNTY CHARACTERISTICS

\begin{tabular}{|c|c|c|c|c|c|}
\hline & Base & $\begin{array}{c}\text { Hunger } \\
\text { deaths/population }\end{array}$ & $\begin{array}{c}\text { Hunger deaths/all } \\
\text { deaths }\end{array}$ & $\begin{array}{l}\text { IMR for nutrition- } \\
\text { related deaths }\end{array}$ & $\begin{array}{l}\text { Share with } \\
\text { low income }\end{array}$ \\
\hline & & \multicolumn{4}{|c|}{ Top quartile counties (most disadvantaged) } \\
\hline FS share IU-5 & $\begin{array}{c}-0.294 * * * \\
(0.107)\end{array}$ & $\begin{array}{c}-0.367 \\
(0.300)\end{array}$ & $\begin{array}{c}-0.424 \\
(0.277)\end{array}$ & $\begin{array}{c}-0.243^{*} \\
(0.144)\end{array}$ & $\begin{array}{c}-0.426 \\
(0.226)\end{array}$ \\
\hline $\begin{array}{l}\text { Observations } \\
R^{2}\end{array}$ & $\begin{array}{l}8,246 \\
0.26\end{array}$ & $\begin{array}{l}2,217 \\
0.32\end{array}$ & $\begin{array}{l}2,428 \\
0.31\end{array}$ & $\begin{array}{l}3,685 \\
0.28\end{array}$ & $\begin{array}{l}4,180 \\
0.24\end{array}$ \\
\hline & & \multicolumn{4}{|c|}{ Bottom quartile counties (least disadvantaged) } \\
\hline FS share IU-5 & & $\begin{array}{c}-0.123 \\
(0.175)\end{array}$ & $\begin{array}{c}-0.123 \\
(0.175)\end{array}$ & $\begin{array}{c}0.202 \\
(0.215)\end{array}$ & $\begin{array}{c}-0.351 \\
(0.181)\end{array}$ \\
\hline $\begin{array}{l}\text { Observations } \\
R^{2}\end{array}$ & & $\begin{array}{l}2,312 \\
0.29\end{array}$ & $\begin{array}{l}2,312 \\
0.25\end{array}$ & $\begin{array}{l}1,174 \\
0.38\end{array}$ & $\begin{array}{l}1,135 \\
0.29\end{array}$ \\
\hline
\end{tabular}

Notes: Each parameter is from a separate regression of the outcome variable on FSP exposure (share of months between conception and age five that FSP is in the county). The sample comes from the 1968-2009 PSID and includes heads and wives born between 1956 and 1981 who are between 18 and 53 years old (or 24-53 for economic outcomes). Quartiles are assigned using 1962 and 1963 counts of county deaths (columns 2-4) and share county population with income less than \$3,000 (in 1960 US\$). Estimates are weighted using the PSID weights and clustered on county of birth. The models control for individual demographics, family background, and fixed effects for year of birth, year of interview, county, state-specific linear cohort, and 1960 county characteristics interacted with linear cohort. Standard errors are in parentheses.

*** Significant at the 1 percent level.

** Significant at the 5 percent level.

* Significant at the 10 percent level.

Table 9-Triple-Difference Estimates for Metabolic Syndrome and Economic Self-Sufficiency, Full SAmple

\begin{tabular}{lccc}
\hline \hline & $\begin{array}{c}\text { Metabolic } \\
\text { syndrome (index) }\end{array}$ & Good health & $\begin{array}{c}\text { Economic self- } \\
\text { sufficiency (index) }\end{array}$ \\
\hline FS share IU-5 $\times p_{g}$ & $-0.438^{* *}$ & $0.292 * *$ & 0.400 \\
FS share IU-5 & $(0.204)$ & $(0.133)$ & $(0.323)$ \\
& -0.032 & -0.021 & -0.045 \\
Mean of dependent variable & $(0.073)$ & $(0.051)$ & $(0.083)$ \\
Observations & -0.08 & 0.68 & 0.69 \\
$R^{2}$ & 19,948 & 54,787 & 43,117 \\
\hline
\end{tabular}

Notes: Each parameter is from a separate regression of the outcome variable on FSP exposure (share of months between conception and age five that FSP is in the county) interacted with a group-specific FSP participation rate. The sample comes from the 1968-2009 PSID and includes heads and wives born between 1956 and 1981 who are between 18 and 53 years old (or 24-53 for economic outcomes). Estimates are weighted using the PSID weights and clustered on county of birth. The models control for individual demographics, family background, and fixed effects for year of birth, year of interview, county, state-specific linear cohort, and 1960 county characteristics interacted with linear cohort. Standard errors are in parentheses.

*** Significant at the 1 percent level.

** Significant at the 5 percent level.

* Significant at the 10 percent level.

each group $\mu_{g}$, and (although not shown in (2)), interactions of $P_{g}$ with demographics, year of birth and interview fixed effects, and 1960 county characteristic trends. The coefficient on the main effect for food stamp treatment $\varphi$ represents the impact for a participation rate of zero; therefore we expect this coefficient to be zero. In this 
triple-difference model, the maintained assumption is that there are no differential trends for high participation versus low participation groups within early versus late implementing counties.

Results for this specification are presented in Table 9. Note that the main treatment variable, FS Share $I U-5$, is interacted with the participation rate and therefore the coefficient represents the impact of FSP exposure on health and economic outcome for someone who takes up the program. Thus, these are treatment-on-the-treated estimates and should be compared to the inflated estimates in the high participation sample.

The results in Table 9 show that full exposure to food stamps through age five leads to a 0.4 standard deviation reduction in metabolic syndrome and an about 30-percentage-point increase in reporting good health. Economic self-sufficiency is improved, but not significantly. The magnitudes are similar but somewhat smaller than the comparable (treatment on the treated) results for the high participation sample. Further, as expected the main effect on food stamp exposure (effect implied for a group with a participation rate of zero) is very small and insignificant.

\section{Putting the Effect Size into Context}

Animal lab experiments can provide "proof of concept" of biological plausibility. Presenting effect magnitudes has not typically been a focus in these studies, e.g., standard deviations or other information required to calculate effect sizes are often omitted. Nonetheless, when they can be assessed, effect sizes are quite large. For example, in a laboratory study of 30 pregnant rats, Vickers et al. (2000) reduced the nutritional intake of the treatment group by 30 percent. The offspring's adult weight increased 80 percent of the control group's standard deviation, while impacts on length, fat measures, and kidney and liver sizes were over one standard deviation.

What we view as the closest evidence, both in the quality of the design and broad similarity to our food stamps treatment, comes from the handful of high-quality evaluations of early life policy interventions. In the Carolina Abecedarian (ABC) Project, children were randomly assigned to a cognitively and socially stimulating environment for eight hours per day during their first five years of life. Children were also given two meals and a snack at the childcare center, along with primary medical care. In their mid-30s, no males in the treatment group had metabolic syndrome, compared with 25 percent of the control group (Campbell et al. 2014). There were also significant and large (over 40 percentage points) declines in hypertension, and improvements in high-density lipoprotein (HDL) cholesterol and vitamin D deficiency. Fewer results were statistically significant among women, though the point estimates also suggest very large effects on outcomes such as abdominal obesity and the Framingham cardiovascular risk score. ${ }^{41}$

Another influential strand of evidence considers an experimental nutrition supplementation in Guatemala in the 1970s. Children up to age seven were given access to a protein drink that increased average caloric intake by 10 percent and protein

\footnotetext{
${ }^{41}$ Aizer et al. (2016) examine the Mothers Pension program, a cash welfare program that preceded the AFDC program. Boys exposed to the additional income as children (on average 12-25 percent of family income and for a three-year period) experienced a 50 percent reduction in underweight as well as a large reduction in mortality.
} 
intake by almost 30 percent. In adulthood, women had increased educational attainment of more than one grade (more than 50 percent of a standard deviation), and males who were exposed to the treatment between birth and age three saw their wages increase by 46 percent (Maluccio et al. 2009; Hoddinott et al. 2008). Men showed a significant, approximately 30 percent of a standard deviation decline in metabolic syndrome and body mass index, and 40 percent of a standard deviation decline in waist circumference (Stein et al. 2006). ${ }^{42}$

In sum, policy interventions that improve early childhood environments can generate large long-term effects, frequently the same magnitude or larger than what we find for food stamps.

\section{Does the Timing of Treatment Matter?}

The results thus far measure food stamp treatment as the share of time between conception and age five that food stamps is in place in the county of birth. There are two reasons to explore alternative specifications for exposure to the food stamps rollout. First, as discussed above, the nature of our treatment is such that the policy turns on and does not turn off. Therefore, when a child is treated in early life (e.g., zero to five years old) they are also treated in later childhood. Our estimates, therefore, also reflect exposure beyond age five; exploring the timing of impacts may help in interpreting the magnitudes of the effects. Second, the biological and economic literature is not clear on when exposure to the safety net matters. Thus, exploring alternative specifications for food stamp exposure can provide new evidence on this important issue.

We explore this using an event study model, and for this we return to the high-participation sample. The event study model allows us to explore the timing of food stamp exposure more systematically and to evaluate the validity of the research design. In particular, these estimates allow us to explore nonparametrically the relationship between age at initial rollout and adult outcomes. In addition, we can use these results to rule out the presence of pre- (or post-) trends that could lead to spurious findings. Specifically, we allow for the impact of FSP program to vary with the age at FSP introduction in their county of birth. For example, individuals born in 1970 in a county that implemented food stamps in 1975 would have an event time of 5. They would have event time of -5 if FSP was implemented in their birth county in 1965 (and thus they were exposed during their entire childhood).

We estimate a version of model (1) where the main FSP effect $\left(F S P_{c b}\right)$ is replaced with a series of dummies for based on two-year intervals of age at FSP introduction (e.g., age $0-1,2-3,4-5$, and so on) with age 10-11 as the omitted year. The end points are open brackets ( 5 or more years prior to birth on the left, age 12 or later on the right) which helps reduce the collinearity between event time and birth year. Because the sample is unbalanced in event time we focus on the event study coefficients inside these unbalanced endpoints (Kline 2012). We present results for metabolic syndrome index in Figure 3 and for the economic self-sufficiency index in Figure 4. For economic self-sufficiency, we estimate the event study for women

\footnotetext{
${ }^{42}$ Stein et al. (2006) report intention-to-treat impacts, and to make these comparable to our estimates we inflate by their 0.65 estimate of the share of children who ever participated in the program.
} 


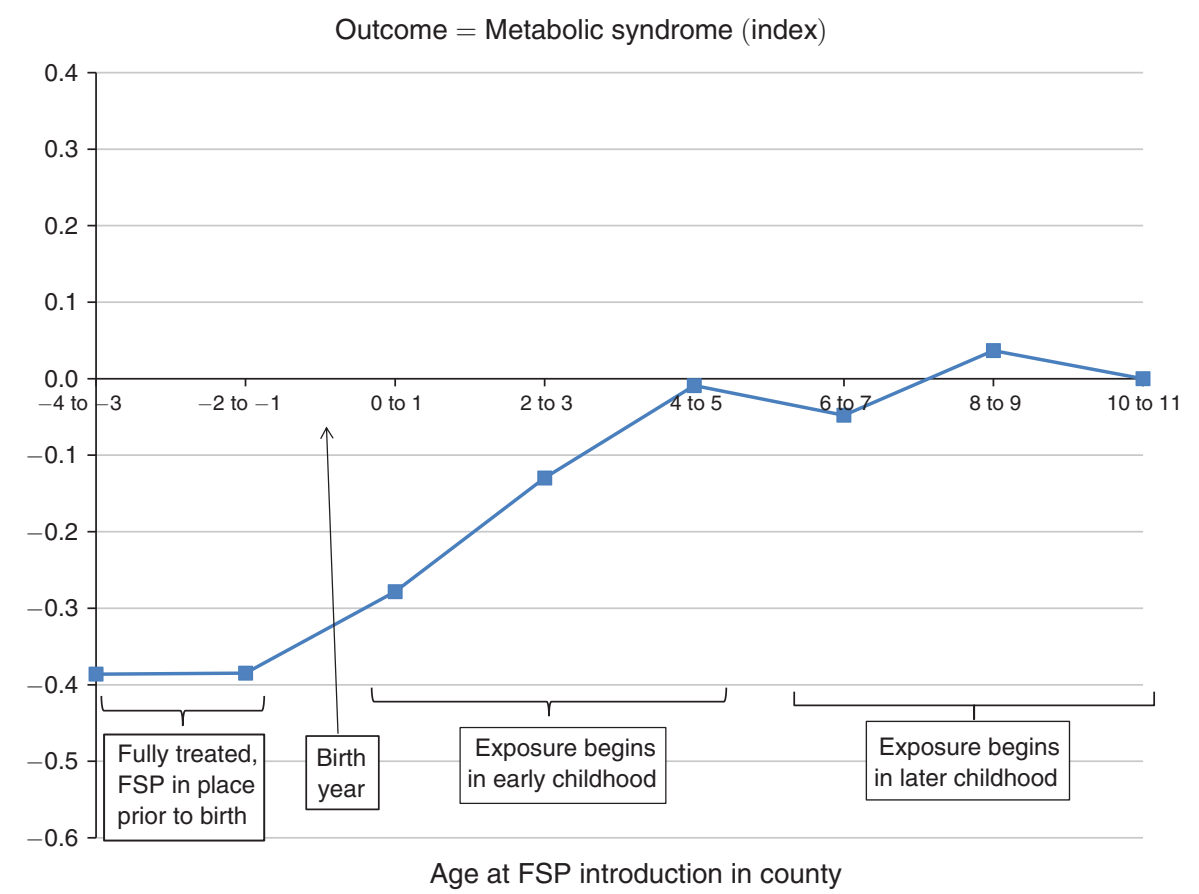

Figure 3. Event Study Estimates of the Impact of FSP Exposure on Metabolic Syndrome Index (High Participation Sample)

Notes: The figure plots coefficients from an event-study analysis. Event time is defined as age when FSP is implemented in the birth county. The models are estimated for the sample of individuals born into families where the head has less than a high school education. Age 10-11 is the omitted year so estimates are relative to that point. See the text for a description of the model.

given that we find zero impact on economic self-sufficiency for men (Table 6). Note that these are the reverse of a typical event study graph, in that negative "event time" is the case where a person was fully treated (food stamps was in place in their county prior to birth). Further, treatment (exposure to the program) increases as we move from the right (treated in later life) to the left (treated in early life). Finally, as we have said before, once the treatment turns on it does not turn off.

While we do not have a strong prediction about the precise shape of the treatment effects, our hypothesis is that the impact of the FSP treatment should decline as age at initial exposure increases. Or to state the reverse, the younger the initial age of exposure the larger the (cumulative) effect of the FSP. If exposure in later childhood does not matter, then the event study coefficients should be flat on the right end of the graph (suggesting no "pretrend"). Eventually, once we hit the point in early childhood when exposure matters, a movement left (toward earlier initial exposure) should reduce the metabolic syndrome index (or increase economic self-sufficiency). Eventually, the event study should be flat once exposure is "complete" (exposure is prior to conception or an event time of -1 or before).

The results in Figure 3 are highly consistent with these predictions and quite encouraging for our research design. They show that the largest effects of the food stamp treatment (in this case a reduction in metabolic syndrome is good and so a 


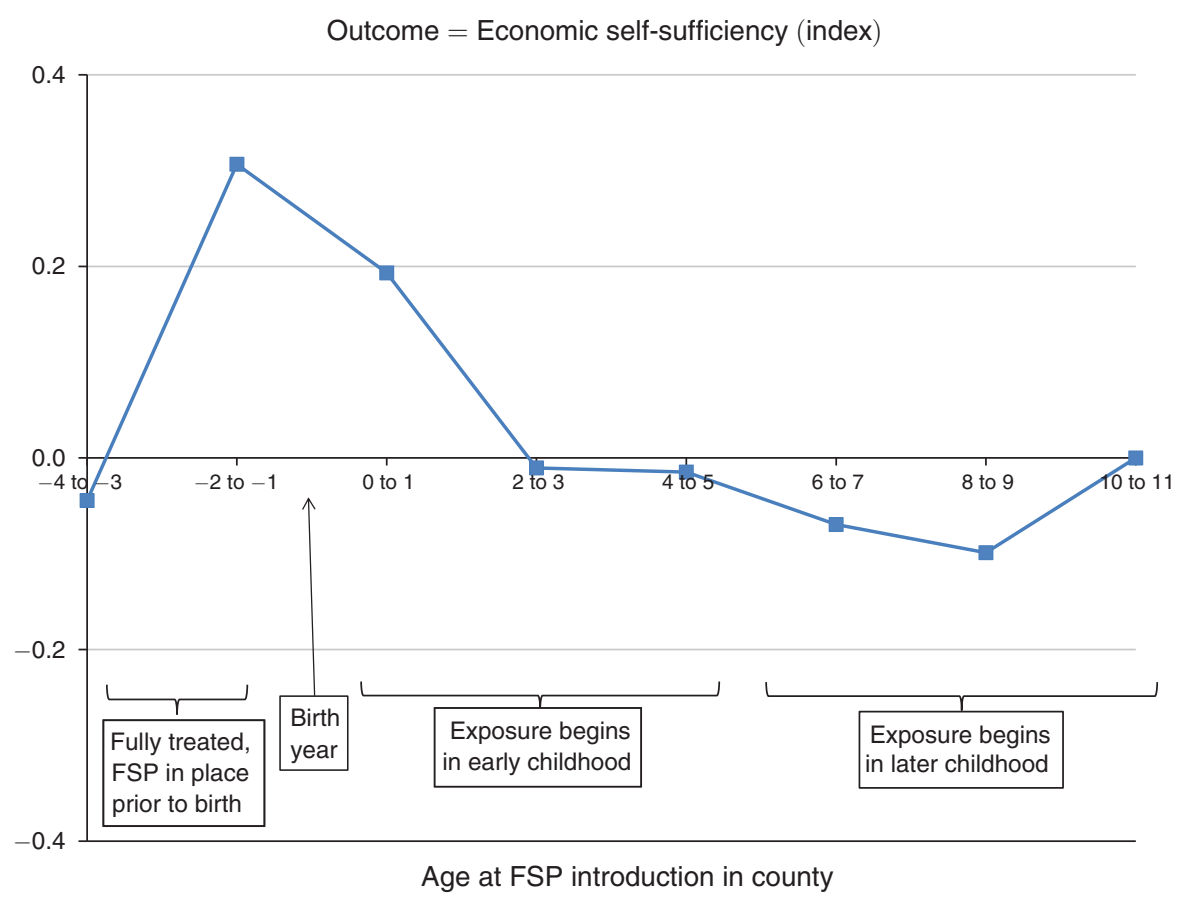

Figure 4. Event Study Estimates of the Impact of FSP Exposure on Economic Self-Sufficiency (High Participation Sample)

Notes: The figure plots coefficients from an event-study analysis. Event time is defined as age when FSP is implemented in the birth county. The models are estimated for the sample of individuals born into families where the head has less than a high school education. Age 10-11 is the omitted year so estimates are relative to that point. See the text for a description of the model.

beneficial effect is represented by a negative impact) are to those who are treated in utero and early childhood. The improvement in health is steepest with additional exposure between conception and age four or five. The results suggest that the adult health impacts of the FSP are minimal if the child is exposed after age five. It is notable that for negative event time (fully exposed) the line is flat (and similarly that it is flat across older ages): this is an important result that can rule out that our estimates are identified by cohort trends within counties.

The event study figure for economic outcomes for women is provided in Figure 4. The event study shows results consistent with a positive effect of the FSP on economic outcomes again with the most beneficial effects in early life (in utero to age two to three). There is also some evidence that increasing exposure between ages eight to nine and four to five. We note that the theory linking FSP to economic self-sufficiency is less well developed in the literature and we do not have strong priors on what the graph should look like. On one hand, increased resources during the in utero period or early life may improve brain development and yield a larger gain to long-term economic outcomes. On the other hand, to the extent that improved nutrition during schooling years increases a child's ability to pay attention in school (or even to attend school), we would expect to see positive impacts even if the program was introduced at a later age. It is important to interpret the coefficients by age 
with some caution because we do not have an experiment where the older children receive treatment but the younger ones do not. The event study results are consistent with the positive estimated impact in Table 5, and the results suggest that positive effects are not concentrated only in utero.

\section{Conclusion}

In this paper, we present new evidence that expanding economic resources in utero and in early childhood can lead to significant improvement in adult health and, for women, economic outcomes. In particular, we use the rollout of the most important cash or near cash safety net program in the US, the Food Stamp Program. We find that access to food stamps in utero and in early childhood leads to significant reductions in metabolic syndrome conditions (obesity, high blood pressure, heart disease, diabetes) in adulthood and, for women, increases in economic self-sufficiency (increases in educational attainment, earnings, income, and decreases in welfare participation). Further, we provide new evidence on when exposure to additional resources matters: the gains are large and increasing with exposure to age five. Beyond that point the additional resources do not translate into improved adult health outcomes. These results pass several robustness tests including controlling for other county-year of birth controls for the Great Society period, alternate ways of targeting the population that is highly impacted by the program, various placebo tests, and event study models.

Given the near-cash nature of food stamp vouchers (Hoynes and Schanzenbach 2009), the exact biological mechanisms that lead to the long-run improvement in health and human capital is not clear. The availability of food stamps leads to more food consumption (Hoynes and Schanzenbach 2009; Currie 2003) and thus one clear channel is through an increase in nutrition in the critical in utero and early life period. Additionally, recent work suggests that additional income can lead to reductions in cortisol in mothers, reducing biological harm due to persistent stress (Aizer, Stroud, and Buka forthcoming; Evans and Garthwaite 2014).

Our analysis finds strong, long-term improvements in health, and, for women, economic outcomes, from increasing the economic resources in low-income households with young children through transfers via the Food Stamp Program. The results suggest that a robust safety net insuring young children against low levels of income is an investment in their long-run human capital, with internal and external benefits that to date not been quantified. The past four decades have provided strong productivity growth in the US yet earnings and family incomes have fallen in real terms for the bottom third or quarter of the distribution. More families will be relying on food stamps, the Earned Income Tax Credit, and Medicaid to counter these trends. Advancing our knowledge about the short- and long-run effects of these programs is critical in light of their growing importance. 


\section{REFERENCES}

Acemoglu, Daron, David H. Autor, and David Lyle. 2004. "Women, War, and Wages: The Effect of Female Labor Supply on the Wage Structure at Midcentury.” Journal of Political Economy 112 (3): 497-551.

Aizer, Anna, Shari Eli, Joseph Ferrie, and Adriana Lleras-Muney. 2016. "The Long Run Impact of Cash Transfers to Poor Families." American Economic Review 106 (4): 935-71.

Aizer, Anna, Laura Stroud, and Stephen Buka. Forthcoming. "Maternal Stress and Child Outcomes: Evidence From Siblings." Journal of Human Resources.

Almond, Douglas. 2006. "Is the 1918 Influenza Pandemic Over? Long-Term Effects of In Utero Influenza Exposure in the Post-1940 U.S. Population.” Journal of Political Economy 114 (4): 672-712.

Almond, Douglas, Kenneth Chay, and Michael Greenstone. 2007. "Civil Rights, the War on Poverty, and Black-White Convergence in Infant Mortality in the Rural South and Mississippi." MIT Working Paper 07-04.

Almond, Douglas, Kenneth Chay, and David S. Lee. 2005. “The Costs of Low Birth Weight.” Quarterly Journal of Economics 120 (3): 1031-83.

Almond, Douglas, and Janet Currie. 2011a. "Human Capital Development Before Age Five.” In Handbook of Labor Economics, Vol. 4B, edited by Orley Ashenfelter and David Card, 1315-1486. New York: Elsevier.

Almond, Douglas, and Janet Currie. 2011b. "Killing Me Softly: The Fetal Origins Hypothesis." Journal of Economic Perspectives 25 (3): 153-72.

Almond, Douglas, Janet Currie, and Mariesa Hermann. 2012. "From Infant to Mother: Early Disease Environment and Future Maternal Health.” Labour Economics 19 (4): 475-83.

Almond, Douglas, Lena Edlund, and Mårten Palme. 2009. "Chernobyl's Subclinical Legacy: Prenatal Exposure to Radioactive Fallout and School Outcomes in Sweden." Quarterly Journal of Economics 124 (4): 1729-72.

Almond, Douglas, Hilary W. Hoynes, and Diane Whitmore Schanzenbach. 2011. "Inside the War on Poverty: The Impact of Food Stamps on Birth Outcomes." Review of Economics and Statistics 93 (2): 387-403.

Almond, Douglas, and Bhashkar Mazumder. 2011. "Health Capital and the Prenatal Environment: The Effect of Ramadan Observance during Pregnancy." American Economic Journal: Applied Economics 3 (4): 56-85.

Anderson, Michael L. 2008. "Multiple Inference and Gender Differences in the Effects of Early Intervention: A Reevaluation of the Abecedarian, Perry Preschool, and Early Training Projects." Journal of the American Statistical Association 103 (484): 1481-95.

Andreski, Patricia, Katherine McGonagle, and Robert Schoeni. 2009. "An Analysis of the Quality of the Health Data in the Panel Study of Income Dynamics.” PSID Technical Series Paper 09-02.

Bailey, Martha J. 2012. "Reexamining the Impact of Family Planning Programs on US Fertility: Evidence from the War on Poverty and the Early Years of Title X." American Economic Journal: Applied Economics 4 (2): 62-97.

Bailey, Martha J., and Andrew Goodman-Bacon. 2015. “The War on Poverty's Experiment in Public Medicine: Community Health Centers and the Mortality of Older Americans." American Economic Review 105 (3): 1067-1104.

Bane, Mary Jo, and David T. Ellwood. 1994. Welfare Realities: From Rhetoric to Reform. Cambridge, MA: Harvard University Press.

Banerjee, Abhijit, Esther Duflo, Gilles Postel-Vinay, and Tim Watts. 2010. "Long-Run Health Impacts of Income Shocks: Wine and Phylloxera in Nineteenth-Century France." Review of Economics and Statistics 92 (4): 714-28.

Barker, D. J. P. 1992. "Fetal and Infant Origins of Adult Disease." British Medical Journal 301 (6761): 1111.

Barreca, Alan I. 2010. "The Long-Term Economic Impact of In Utero and Postnatal Exposure to Malaria." Journal of Human Resources 45 (4): 865-92.

Berry, Jeffrey M. 1984. Feeding Hungry People: Rulemaking in the Food Stamp Program. New Brunswick, NJ: Rutgers University Press.

Bharadwaj, Prashant, Katrine Vellesen Løken, and Christopher Neilson. 2013. "Early-Life Health Interventions and Academic Achievement." American Economic Review 103 (5): 1862-91.

Bitler, Marianne, and Hilary Hoynes. 2010. "The State of the Safety Net in the Post-Welfare Reform Era." Brookings Papers on Economic Activity (Fall): 71-127.

Bitler, Marianne, and Hilary Hoynes. 2015. "Heterogeneity in the Impact of Economic Cycles and the Great Recession: Effects within and across the Income Distribution." American Economic Review 105 (5): 154-60. 
Bleakley, Hoyt. 2007. "Disease and Development: Evidence from Hookworm Eradication in the American South.” Quarterly Journal of Economics 122 (1): 73-117.

Bozzoli, Carlos, Angus Deaton, and Climent Quintana-Domeque. 2009. "Adult Height and Childhood Disease." Demography 46 (4): 647-69.

Brown, David W., Amanda E. Kowalski, and Ithai Z. Lurie. 2015. "Medicaid as an Investment in Children: What is the Long-Term Impact on Tax Receipts?" National Bureau of Economic Research Working Paper 20835.

Campbell, Frances, Gabriella Conti, James J. Heckman, Seong Hyeok Moon, Rodrigo Pinto, Elizabeth Pungello, and Yi Pan. 2014. "Early Childhood Investments Substantially Boost Adult Health." Science 343 (6178): 1478-85.

Carneiro, Pedro, and Rita Ginja. 2014. "Long-Term Impacts of Compensatory Preschool on Health and Behavior: Evidence from Head Start." American Economic Journal: Economic Policy 6 (4): 135-73.

Cascio, Elizabeth, Nora Gordon, Ethan Lewis, and Sarah Reber. 2010. "Paying for Progress: Conditional Grants and the Desegregation of Southern Schools." Quarterly Journal of Economics 125 (1): 445-82.

Case, Anne, Darren Lubotsky, and Christina Paxson. 2002. "Economic Status and Health in Childhood: The Origins of the Gradient." American Economic Review 92 (5): 1308-34.

Case, Anne, and Christina Paxson. 2008. "Stature and Status: Height, Ability, and Labor Market Outcomes." Journal of Political Economy 116 (3): 499-532.

Chay, Kenneth, Jonathan Guryan, and Bhashkar Mazumder. 2009. "Birth Cohort and the BlackWhite Achievement Gap: The Roles of Access and Health Soon after Birth.” National Bureau of Economic Research Working Paper 15078.

Chen, Yuyu and Li-An Zhou. 2007. "The Long Term Health and Economic Consequences of the 19591961 Famine in China." Journal of Health Economics 26 (4): 659-81.

Chetty, Raj, John N. Friedman, Nathaniel Hilger, Emmanuel Saez, Diane Whitmore Schanzenbach, and Danny Yagan. 2011. "How Does Your Kindergarten Classroom Affect Your Earnings? Evidence from Project STAR." Quarterly Journal of Economics 126 (4): 1593-1660.

Citizens' Board of Inquiry. 1968. Hunger, USA: A Report By the Citizens' Board of Inquiry into Hunger and Malnutrition in the United States. Boston: Beacon Press.

Clark, Damon, and Heather Royer. 2013. "The Effect of Education on Adult Mortality and Health: Evidence from Britain.” American Economic Review 103 (6): 2087-2120.

Currie, Janet. 2003. "U.S. Food and Nutrition." In Means-Tested Transfer Programs in the United States, edited by Robert A. Moffitt, 199-290. Chicago: University of Chicago Press.

Currie, Janet. 2009. "Healthy, Wealthy, and Wise: Socioeconomic Status, Poor Health in Childhood, and Human Capital Development.” Journal of Economic Literature 47 (1): 87-122.

Currie, Janet, and Enrico Moretti. 2008. "Did the Introduction of Food Stamps Affect Birth Outcomes in California?" In Making Americans Healthier: Social and Economic Policy as Health Policy, edited by Robert F. Schoeni et al., 122-42. New York: Russell Sage Foundation.

Dahl, Gordon B., Andreas Ravndal Kostøl, and Magne Mogstad. 2014. "Family Welfare Cultures." Quarterly Journal of Economics 129 (4): 1711-52.

Dahl, Gordon B., and Lance Lochner. 2012. "The Impact of Family Income on Child Achievement: Evidence from the Earned Income Tax Credit." American Economic Review 102 (5): 1927-56.

Dynarski, Susan, Joshua Hyman, and Diane Whitmore Schanzenbach. 2013. "Experimental Evidence on the Effect of Childhood Investments on Postsecondary Attainment and Degree Completion." Journal of Policy Analysis and Management 32 (4): 692-717.

Eisinger, Peter K. 1998. Toward an End to Hunger. Washington, DC: Brookings Institution Press.

Evans, William N., and Craig L. Garthwaite. 2014. "Giving Mom a Break: The Effect of Higher EITC Payments on Maternal Health.” American Economic Journal: Economic Policy 6 (2): 258-90.

Field, Erica, Omar Robles, and Maximo Torero. 2009. "Iodine Deficiency and Schooling Attainment in Tanzania." American Economic Journal: Applied Economics 1 (4): 140-69.

Finkelstein, Amy, and Robin McKnight. 2008. "What Did Medicare Do? The Initial Impact of Medicare on Mortality and Out of Pocket Medical Spending." Journal of Public Economics 92 (7): 1644-68.

Fitzsimons, Emla, and Marcos Vera-Hernández. 2014. "Food for Thought? Breastfeeding and Child Development.” Institute of Education, University College London Working Paper 14-04.

Galer-Unti, Regina. 1995. Hunger and Food Assistance Policy in the United States. New York: Garland Publishing Inc.

Glied, Sherry, and Matthew Neidell. 2010. "The Economic Value of Teeth." Journal of Human Resources 45 (2): 468-96.

Gluckman, Peter, and Mark Hanson. 2004. The Fetal Matrix: Evolution, Development, and Disease. Cambridge: Cambridge University Press. 
Hoddinott, John, John A. Maluccio, Jere R. Behrman, Rafael Flores, and Reynaldo Martorell. 2008. "Effect of a Nutrition Intervention During Early Childhood on Economic Productivity in Guatemalan Adults." Lancet 371 (9610): 411-16.

Hoynes, Hilary, Marianne Page, and Ann Huff Stevens. 2011. "Can Targeted Transfers Improve Birth Outcomes? Evidence from the Introduction of the WIC Program.” Journal of Public Economics 95 (7-8): 813-27.

Hoynes, Hilary, and Diane Whitmore Schanzenbach. 2009. "Consumption Reponses to In-Kind Transfers: Evidence from the Introduction of the Food Stamp Program." American Economic Journal: Applied Economics 1 (4): 109-39.

Hoynes, Hilary, and Diane Whitmore Schanzenbach. 2012. "Work Incentives and the Food Stamp Program." Journal of Public Economics 96 (1-2): 151-62.

Hoynes, Hilary, and Diane Whitmore Schanzenbach. Forthcoming. "US Food and Nutrition Programs.” In Means-Tested Transfer Programs, Vol. II, edited by Robert Moffitt. Chicago: University of Chicago Press.

Hoynes, Hilary, Diane Whitmore Schanzenbach, and Douglas Almond. 2016. "Long-Run Impacts of Childhood Access to the Safety Net: Dataset." American Economic Review. http://dx.doi. org/10.1257/aer.20130375.

Internal Revenue Service. 2012. Earned Income Tax Credit Statistics. http://www.eitc.irs.gov/central/ eitcstats/ (accessed September 1, 2012.)

Isen, Adam, Maya Rossin-Slater, and W. Reed Walker. Forthcoming. "Every Breath You Take-Every Dollar You'll Make: The Long-Term Consequences of the Clean Air Act of 1970." Journal of Political Economy.

Kline, Patrick. 2012. "The Impact of Juvenile Curfew Laws on Arrests of Youth and Adults.” American Law and Economics Review 14 (1): 44-67.

Kling, R. Jeffrey, Jeffrey B. Liebman, and Lawrence F. Katz. 2007. "Experimental Analysis of Neighborhood Effects." Econometrica 75 (1): 83-119.

Lewit, Eugene M., and Nancy Kerrebrock. 1997. "Population-Based Growth Stunting." Future of Children 7 (2): 149-56.

Lhila, Aparna, and Kosali I. Simon. 2008. "Prenatal Health Investment Decisions: Does the Child's Sex Matter?” Demography 45 (4): 885-905.

Lleras-Muney, Adriana. 2005. "The Relationship between Education and Adult Mortality in the United States." Review of Economic Studies 72 (1): 189-221.

Ludwig, Jens, and Douglas L. Miller. 2007. "Does Head Start Improve Children's Life Chances? Evidence from a Regression Discontinuity Design.” Quarterly Journal of Economics 122 (1): 159-208.

Maccini, Sharon, and Dean Yang. 2009. "Under the Weather: Health, Schooling, and Economic Consequences of Early-Life Rainfall.” American Economic Review 99 (3): 1006-26.

MacDonald, Maurice. 1977. Food, Stamps, and Income Maintenance. Madison, WI: Institute for Poverty Research.

Maluccio John A., John Hoddinott, Jere R. Behrman, Reynaldo Martorell, Agnes R. Quisumbing, and Aryeh D. Stein. 2009. “The Impact of Improving Nutrition during Early Childhood on Education among Guatemalan Adults.” Economic Journal 119 (537): 734-63.

McCance, R. A. 1962. “Food, Growth, and Time.” Lancet 280 (7258): 671-76.

McDowell, Margaret A., Cheryl D. Fryar, Cynthia L. Ogden, and Katherine M. Flegal. 2008. "Anthropometric Reference Data for Children and Adults: United States, 2003-2006.” National Health Statistics Reports 10. http://ghk.h-cdn.co/assets/cm/15/11/550017f045e74_-_nhsr010.pdf (accessed October 26, 2015).

Meyer, Bruce D., and Laura R. Wherry. 2012. "Saving Teens: Using a Policy Discontinuity to Estimate the Effects of Medicaid Eligibility.” National Bureau of Economic Research Working Paper 18309.

Milligan, Kevin, and Mark Stabile. 2011. "Do Child Tax Benefits Affect the Well-Being of Children? Evidence from Canadian Child Benefit Expansions.” American Economic Journal: Economic Policy 3 (3): 175-205.

Nilsson, J. Peter. 2009. “The Long-Term Effects of Early Childhood Lead Exposure: Evidence from the Phase-Out of Leaded Gasoline." Unpublished.

Nilsson, J. Peter. Forthcoming. "Alcohol Availability, Prenatal Conditions, and Long-Term Economic Outcomes." Journal of Political Economy.

Painter, Rebecca C., Tessa J. Roseboom, and Otto P. Bleker. 2005. "Prenatal Exposure to the Dutch Famine and Disease in Later Life: An Overview." Reproductive Toxicology 20 (3): 345-52.

Reyes, Jessica Wolpaw. 2007. "Environmental Policy as Social Policy? The Impact of Childhood Lead Exposure on Crime.” BE Journal of Economic Analysis and Policy 7 (1). 
Short, Kathleen. 2014. The Research Supplemental Poverty Measure: 2013. Current Population Reports P60-251. US Census Bureau.

Stein, Aryeh D., Meng Wang, Manuel Ramirez-Zea, Rafael Flores, Ruben Grajeda, Paul Melgar, Usha Ramakrishnan, and Reynaldo Martorell. 2006. "Exposure to a Nutrition Supplementation Intervention in Early Childhood and Risk Factors for Cardiovascular Disease in Adulthood: Evidence from Guatemala." American Journal of Epidemiology 164 (12): 1160-70.

Stein, Zena, Mervyn Susser, Gerhart Saenger, and Francis Marolla. 1975. Famine and Human Development: The Dutch Hunger Winter of 1944-1945. New York: Oxford University Press.

Susser, Ezra S., and Shang P. Lin. 1992. "Schizophrenia after Prenatal Exposure to the Dutch Hunger Winter of 1944-1945." Archives of General Psychiatry 49 (12): 983-88.

Tanner, James M. 1981. "Catch-up Growth in Man.” British Medical Bulletin 37 (3): 233-38.

US Department of Agriculture (USDA). Various years. "Food Stamp Program, Year-End Participation and Bonus Coupons Issues." Food and Nutrition Service Technical Report.

US Department of Agriculture (USDA). 2012. "Supplemental Nutrition Assistance Program (SNAP)." Food and Nutrition Service. http://www.fns.usda.gov/pd/SNAPsummary.htm (accessed September 1, 2012).

US Department of Health and Human Services. 2012. “TANF Financial Data FY 1997-2008.” Assistant Secretary for Planning and Evaluation. http://www.acf.hhs.gov/programs/ofs/data/index.html (accessed September 1, 2012).

van den Berg, Gerard J., Maarten Lindeboom, and France Portrait. 2006. "Economic Conditions Early in Life and Individual Mortality." American Economic Review 96 (1): 290-302.

Vickers, Mark H., Bernhard H. Breier, Wayne S. Cutfield, Paul L. Hofman, and Peter D. Gluckman. 2000. "Fetal Origins of Hyperphagia, Obesity, and Hypertension and Postnatal Amplification by Hypercaloric Nutrition." American Journal of Physiology, Endocrinology, and Metabolism 279 (1): E83-E87. 


\section{This article has been cited by:}

1. Stephen B. Billings, Kevin T. Schnepel. 2018. Life after Lead: Effects of Early Interventions for Children Exposed to Lead. American Economic Journal: Applied Economics 10:3, 315-344. [Abstract] [View PDF article] [PDF with links]

2. Petra Persson, Maya Rossin-Slater. 2018. Family Ruptures, Stress, and the Mental Health of the Next Generation. American Economic Review 108:4-5, 1214-1252. [Abstract] [View PDF article] [PDF with links]

3. Randall Akee, William Copeland, E. Jane Costello, Emilia Simeonova. 2018. How Does Household Income Affect Child Personality Traits and Behaviors?. American Economic Review 108:3, 775-827. [Abstract] [View PDF article] [PDF with links]

4. Jonas Hjort, Mikkel Sølvsten, Miriam Wüst. 2017. Universal Investment in Infants and Long-Run Health: Evidence from Denmark's 1937 Home Visiting Program. American Economic Journal: Applied Economics 9:4, 78-104. [Abstract] [View PDF article] [PDF with links]

5. David Simon. 2016. Does Early Life Exposure to Cigarette Smoke Permanently Harm Childhood Welfare? Evidence from Cigarette Tax Hikes. American Economic Journal: Applied Economics 8:4, 128-159. [Abstract] [View PDF article] [PDF with links] 